Portland State University

PDXScholar

1974

\title{
A preliminary investigation of the predictive and evaluative capacity of the PARS scale in a community mental health clinic
}

Judith M. Ritter

Portland State University

Follow this and additional works at: https://pdxscholar.library.pdx.edu/open_access_etds

Part of the Social Work Commons

Let us know how access to this document benefits you.

\section{Recommended Citation}

Ritter, Judith M., "A preliminary investigation of the predictive and evaluative capacity of the PARS scale in a community mental health clinic" (1974). Dissertations and Theses. Paper 2152.

https://doi.org/10.15760/etd.2150

This Thesis is brought to you for free and open access. It has been accepted for inclusion in Dissertations and Theses by an authorized administrator of PDXScholar. Please contact us if we can make this document more accessible: pdxscholar@pdx.edu. 
AN ABSTRACT OF THE THESIS OF Judith M. Ritter for the Master of Social Work presented May 17, 1974

Title: A Preliminary Investigation of the Predictive and Evaluative Capacity of the PARS Scale in a Community Mental Health clinic

APPROVED BY MEMBERS OF THE THESIS COMMITTEE

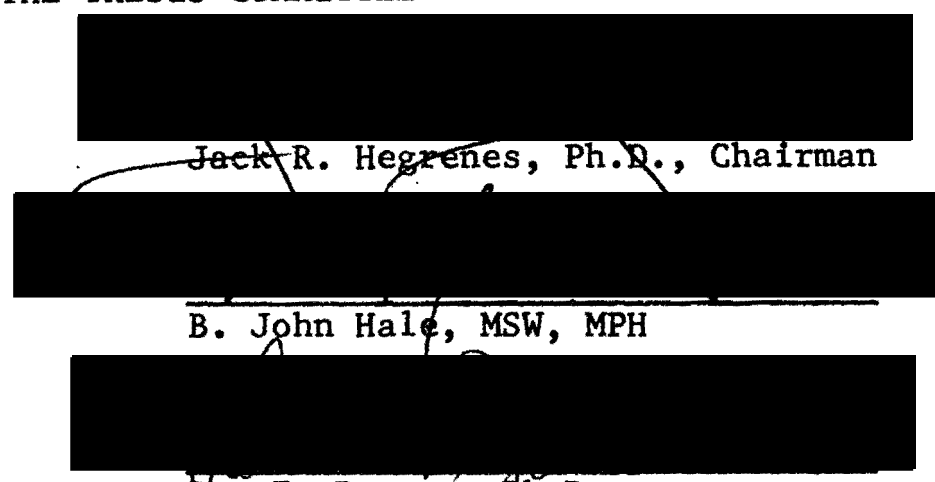

Don F. Pagano, $/$ h.D.

This was a two-part study, employing the self and informant, pre and post treatment, forms of the Personal Adjustment and Role Skills Scale, the PARS Scale. In this study seven of the PARS Scale factors were employed: Interpersonal Involvement, Agitation-Depression, Attention-Confusion, Alcohol-Drug, Outside Social, Household Management (females), and Anxiety (males).

This study was conducted at Delaunay Institute for Mental Health, an outpatient community mental health clinic in a low socioeconomic catchment area.

Part One of the study employed a random sample of seventy applicants, male and female, ages sixteen to sixty-four, who applied 
to Delaunay for treatment services between November of 1972 and July of 1973 and who completed, at least, the self pre treatment PARS Scale. This sample was administered the self and informant pre PARS Scale at initial interview.

In October of 1973, the number of treatment sessions in the three months following initial interview was secured from billing cards. At this same time, therapists at Delaunay were requested to assess the sample on their progress in therapy at that time or at termination. Four categories were possible: great, moderate, slight, and no progress. They were also requested to identify the certainty with which they made the assessment according to: great, moderate, or slight certainty.

Following this, the self pre treatment PARS Scale scores were correlated with number of treatment sessions. No relationship appeared for females between number of treatment sessions and self pre PARS Scale scores. For males, a non significant trend was noted on most factors, indicating that a high self pre PARS score was indicative of fewer treatment sessions. A significant and inverse relationship between the self pre PARS Scale score on Alcohol-Drug and number of treatment sessions occurred for males, indicating that a high score on this factor was suggestive of fewer treatment sessions.

The self pre treatment PARS Scale scores were correlated with therapist assessment of progress in therapy. No relationship appeared for females. For males, no significant relationship 
appeared but a non significant trend was indicated, suggesting that a high self pre PARS Scale score was indicative of a favorable therapist assessment on progress in therapy.

Part Two of the study employed a non random sample of fifteen females who had provided self and informant, pre and post treatment, PARS Scale scores. Post treatment, informant data was notably deficient in this part of the study and prevented the employment of males in the sample. Descriptive data on income, education, marital status, and presenting problem were provided for this sample.

The sample was administered the self and informant, pre treatment, PARS Scale at initial interview. Three months after initial interview they were administered the self and informant, post treatment, PARS Scale if they remained in treatment for at least three months.

As in Part one of this study, number of treatment sessions for the three months following initial interview were secured from the billing cards. In October of 1973, therapists were requested to provide a therapist behavioral assessment with four possible categories: improved, maintained, regressed (therapeutic), regressed (non-therapeutic). This assessment was to be made from recall and/or records at the time the self and informant, post treatment, PARS Scale was administered. Again, therapists were requested to indicate the degree of certainty involved in their assessment.

The relationship between number of treatment sessions and the available self and informant, pre and post treatment, PARS Scale scores was explored. It was found that the self pre PARS score on 
Interpersonal Involvement, the self post PARS score on Alcohol-Drug, and the informant post PARS score on Alcohol-Drug were significantly and inversely related to the number of treatment sessions. High scores on these factors indicated fewer treatment sessions.

The relationship between therapist behavioral assessment and available self and informant, pre and post treatment, PARS Scale scores was explored. Results showed a significant and direct relationship between the self post PARS score on Outside Social, the informant post PARS score on Alcohol-Drug and therapist behavioral assessment. High scores on these factors indicated a favorable therapist behavioral assessment.

Evaluation of treatment services with the PARS Scale in Part Two of this study found the self, pre and post treatment, PARS Scale scores on Attention-Confusion to be the only PARS scores showing significant differences after three months of treatment. None of the remaining self PARS scores and none of three informant PARS scores indicated any significant differences.

It was recommended that the predictive capacity of the PARS Scale not be explored further. Further exploration of the use of the PARS Scale for evaluative purposes was suggested due to the limitations of the research design with regard to specificity and sampling. Finally, exploration of specific and individualized treatment evaluation, suggested by recent psychotherapy research, was encouraged. 
A PRELIMINARY INVESTIGATION OF THE PREDICTIVE AND EVALUATIVE CAPACITY OF THE PARS SCALE

IN A COMMUNITY MENTAL HEALTH CLINIC

by

JUDITH M. RITTER

A thesis submitted in partial fulfillment of the requirements for the degree of

MASTER OF SOCIAL WORK.

Portland State University 1974 
TO THE OFFICE OF GRADUATE STUDIES:

The members of the Committee approve the thesis of Judith $M$. Ritter, presented May 17,-1974.
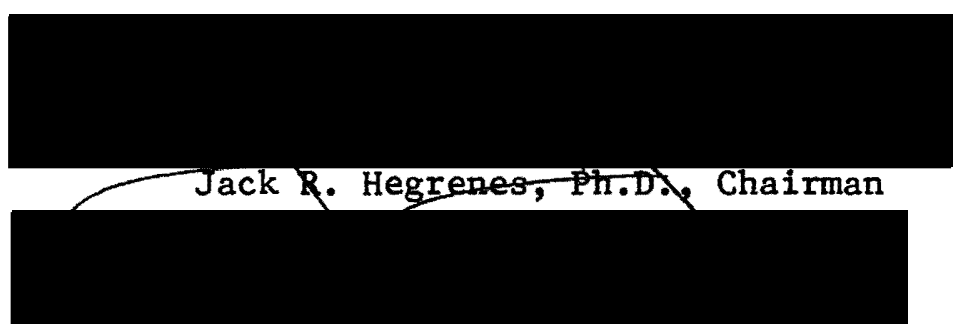

B. John Fle, MSW, MPH

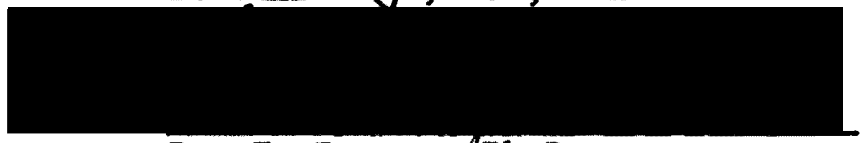

Don F. Pagano, (Ph.D.

APPROVED:

Gordon Fearn, Dean of the School of Social Work

Davìd T. Clark, Dean of Graduate Studies

May 17,1974 


\section{ACKNOWLEDGEMENTS}

I would like to express my gratitude to the staff of Delaunay Institute for Mental Health for their permission to be involved in their continuing evaluative research and for their cooperation and assistance with the present project. Appreciation is expressed to: Elmore Duncan, M.D., Psychiatrist-Director; Delores Morgan, ACSW, Social Worker-Administrator; Thomas E. Dorsey, Ph.D., Psychologist; Jeanette Staebler, ACSW, Social Worker; and Linda Schulz, R.N., Psychiatric Nurse. A special appreciation is expressed to Don F. Pagano, Ph.D., Psychologist, for his willingness to educate with regard to outcome research and his willingness to serve as a member of the thesis committee.

Most of all, I would like to express deep and warm appreciation and affection to Jack R. Hegrenes, Ph.D., Chairman of the thesis committee, for his humor, patience, tolerance, and understanding support with all facets of this research project and for his willingness to assist in all ways and at all times. He has truly made this research project a memorable experience.

Warm gratitude for support and encouraging response is expressed to John Hale, MSW, MPH, who willingly served as a member of the thesis committee.

Appreciation is expressed to Quentin D. Clarkson, Associate Professor at Portland State University, and his daughter, Joyce 
Clarkson, for their assistance with the statistical analyses and processing of data. In addition, a special thanks is deserved by Rolf Priebe, research assistant, who willingly and patiently gave of his time in assisting with the programming of the statistical analyses.

Additional appreciation is expressed to those specialists who willingly gave of their time, information, and material on the PARS Scale and evaluation research in mental health clinics: Robert Ellsworth, Ph.D., Psychologist; Gaylord Thorne, Ph.D., Psychologist; Clinton Goff, Ph.D., Psychologist; and Marshall Hanson of the Department of Mental Hygiene, California.

A special note of thanks belongs to Joan Stiffler, secretary at Delaunay Institute, for the abundance of work she did in collecting and tabulating data and her responsiveness to providing further data on request.

An additional note of thanks belongs to some very special friends and family who have been so tolerant and supportive with my involvement.

Fina1ly, a very sincere appreciation goes to Bonnie Drinkard, typist and advisor, who supported me through the final stages of this project. 
TABLE OF CONTENTS

PAGE

ACKNOWLEDGEMENTS . . . . . . . . . . . . . . •

LIST OF TABLES

CHAPTER

I INTRODUCTION ................. 1

Description of Agency and Catchment Area . . . 1

Focus of Research Project . . . . . . . 2

The Problem ............... 3

General Statement

Null Hypotheses for Parts One and Two of Study

Limitations of Study . . . . . . . . 8

Summary ................. . . 9

II REVIEW OF THE LITERATURE . . . . . . . . . . 10

Prominent Issues in Psychotherapy Research . . 10

Spontaneous Remission, Placebos and Control Groups

Deleterious Effects of Psychotherapy

Methodology

Client Variables and Continuation in

Psychotherapy . . . . . . . . . .

Personality Variables

Intelligence, Education and Social Class

Patient Expectations

Summary 
Outcome Studies and Related Variables . . . .

Duration of Therapy and Treatment Outcome Patient Expectancies and Outcome Studies Personality Variables, Adjustment Factors, and outcome

General Assessments of Psychotherapy

Summary Outcome

Summary and Implications . . . . . . .

Methodology

Findings in Continuation and outcome

$\because$ Research

Implications

III THE PARS SCALE: DEVELOPMENT, DESCRIPTION AND

RESEARCH STUDIES . . . . . . . . . . . . .

Development of the PARS Scale . . . . . .

Description of the PARS-III Scale . . . . .

Research Results with the PARS-III Scale ..

Summary . . . . . . . . . . . . . •

Description of Samples . . . . . . . .

Samples for Part One of Study Samples for Part Two of Study

Methodology . . . . . . . . . . . .

Methodology for Part One of Study

Methodology for Part Two of Study

Summary . . . . . . . . . . . . . .

Findings for Part One of Study . . . . . . 
Findings on Treatment Outcome

Correlations Between Pre Treatment Adjustment and Treatment Outcome

Findings for Part Two of Study .........

Findings on Completed Data Return

Findings on Self Pre and Post PARS Treatment Adjustment

Findings on Informants' Pre and Post PARS Treatment Adjustment

Findings on Treatment outcome

Correlations Between Pre and Post PARS

Treatment Adjustment and Treatment Outcome Factors

Conclusions . . . . . . . . . . . .

Part One of Study

Part Two of Study

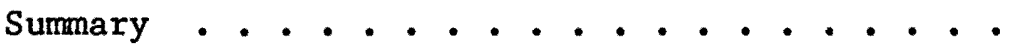

Observations on Findings for Part One of Study

Observations on Findings for Part Two of Study

Observations on Conclusions for Part One of Study

Observations on Conclusions for Part Two of Study

Comments and Conclusions . . . . . . .

Treatment Sessions, Therapișt Assessment, and Therapist Certainty

Number of Treatment Sessions, Therapist Assessment of Adjustment and PARS Scale Factors

Treatment Evaluation and the PARS Scale

Methodology

Summary

Recommendations . . . . . . . . . . . 


\section{LIST OF TABLES}

TABLE

PAGE

I Range, Means, and Standard Deviation of PARS

Factors on Pre Self PARS of Random Sample . .

II Comparison of Mean Scores on the Self Pre PARS

Factors: The Thorne and Goff ${ }^{*}$ Study and the

Delaunay Sample... . . . . . . . . .

III Comparison of Mean Scores on the Pre PARS factors:

Pre Informant Scores of the Mental Health

Clinic Sample and Pre Self Scores from the

Delaunay Sample... . . . . . . . .

IV Range, Means and Standard Deviations for Random Sample on Number of Visits, Progress in Treatment, and Therapist Certainty ........

V Correlations for Random Sample on Number of Visits, Progress in Treatment, and PARS Scale Factors.

VI Range, Means, and Standard Deviations of Female Clients' Self Pre and Post PARS Factors....

VII Range, Means, and Standard Deviations of Female Clients' Informants' Pre and Post PARS

Factors ..................

VIII Range, Means, and Standard Deviations of Number of Sessions, Therapist Behavioral Assessment, and Therapist Certainty on Female Clients...

IX Correlations on Female Clients' Self and Informant Pre and Post PARS Factors with Number of Sessions . . . . . . . . . . . . .

$X$ Correlations on Female Clients' Self and Informant Pre and Post PARS Factors with Therapist Behavioral Assessment . . . . . . . . 


\section{CHAPTER I}

\section{INTRODUCTION}

\section{DESCRIPTION OF AGENCY AND CATCHMENT AREA}

This study was conducted at Delaunay Institute for Mental Health which provides services to outpatients. This clinic is 10cated in North Portland, Oregon, and primarily serves this area, although clients from outside this area may apply for services.

Treatment at Delaunay is based on a broad range of behavior theory and determined by the therapist's facility with the treatment method and the client's needs. Individual, marital, family, and group therapy are offered at the Institute.

The clinic is staffed by a Psychiatrist-Director, a Social Worker-Administrator, two Psychologists, an additional Social Worker, and a Psychiatric Nurse. In addition, Delaunay Institute offers training programs for mental health professionals, especially psychology interns and social work trainees.

With regard to the present study, the most significant feature of the setting is the catchment area Delaunay Institute serves. According to the 1970 census report, it serves a primarily white population between the ages of 19 and 64 . No figures were available from the census report regarding income level. Nevertheless, many of the characteristics of the population of this area would tend to suggest 
that the income level would be lower than the average for the city of Portland.

The catchment area has a considerably higher school dropout rate than the norm for the Portland area. In addition, it has a higher incidence of female-headed families with children, a considerably higher delinquency rate, an increasingly higher incidence of child abuse, and a higher incidence of alcoholism. With only $9.6 \%$ of the population of Multnomah County, this catchment area has $15 \%$ of all the children in the county who receive Aid to Dependent Children through Welfare.

In addition, this catchment area has three low-income housing projects and neighborhoods tend to reflect characteristics of lowincome families. More housing with deficiencies and violations are reported, as well as an extremely high number of abandoned automobiles. Without census figures on income level, it would appear that this is generally a low-income catchment area.

\section{FOCUS OF RESEARCH PROJECT}

In November of 1972, Delaunay Institute inaugurated a new program of evaluation research. At this time they began the administration of three instruments to all new patients for purposes of obtaining pre-therapy and post-therapy behavioral assessment. These included the Personal Adjustment and Role Skills Scale for adults, the Jesness Scale for adolescents, and the Walker Scale for children. 
The adult client was to be assessed at the outset of treatment by himself and an informant on the PARS Scale. Following three months of treatment, the adult was again to be assessed by himself and an informant on the PARS Scale.

The PARS Scale was selected because it had been used previously in Oregon community mental health clinic evaluative studies and was purported to be an inexpensive method of evaluation. In addition, it was felt that the three-month follow-up in the design of this scale would measure change and yet reduce loss of post data, assuming the client would remain in treatment for at least three months. Moreover, the PARS Scale provided for "consumer feedback" of mental health care in tapping the assessment of the informant.

The present study has chosen to focus on the use of the PARS Scale at Delaunay Institute.

\section{THE PROBLEM}

\section{General Statement}

Ongoing problems in psychotherapy research have been those of continuation in therapy and outcome of treatment services. Increasing concern has been expressed regarding the evaluation of treatment services and the methods for evaluation of these services. While there remains considerable controversy and concern regarding how services should be evaluated, Robert E1lsworth (In press), the developer of the PARS Scale, warns: 
Unless significant progress is made in measuring program effectiveness, the mental health professions will find that decisions about program priorities will be made in terms of direct cost factors alone. Programs that cost the least per client will be implemented, and the mental health professional, by default, will have lost much of the opportunity to identify and introduce the most effective treatment approaches for his client. (In press.)

While Ellsworth's admonitions already appear to have merit for mental health care and the funding of it, the problem of measuring treatment effectiveness continues to be exceedingly complex and difficult (Bergin and Garfield, 1971; Kellner, 1967; Strupp and Bergin, 1969).

Nevertheless, past and present research regarding continuation in treatment and outcome of treatment services tends to indicate some gross and consistent findings with regard to these variables. It would appear that the client who is initially in greater distress remains in treatment longer. Levinger (1960) in a review of research on continuation in therapy concludes that, "Regarding $\mathrm{P}$ 's [Patient's] personal attributes, continuers generally have greater discomfort .. ." (p. 49). In addition, Haddock and Mensh (1957) observe that for noncontinuers, termination is frequently unplanned and clients generally fail to show for scheduled appointments. On the other hand, for successful continuers research seems to indicate that the client who is better adjusted at the outset of treatment makes greater progress in treatment. Luborsky, Auerbach, Chandler, Cohen, and Bachrach (1971) in a recent review of outcome research, observe that," . . the more adequate the functioning the better his [the patient's] future course of therapy" (p. 56). 
It is the aim of the present study to explore both the problems of continuation in therapy and treatment outcome. Continuation in therapy is explored through the self pre treatment PARS Scale ratings and their predictive capacity with regard to continuation in treatment and treatment outcome which is assessed by number of treatment sessions and therapist assessment of treatment progress. Treatment outcome is explored through the self and informant, pre and post treatment, PARS Scale ratings and their evaluative capacity. These are related to therapist behavioral assessment, and number of treatment sessions. In addition, some gross suggestions of kinds of client termination are explored.

By way of summary, this study consists of two parts with two different samples. Part One of this study focuses on the predictive capacity of the self pre treatment PARS Scale ratings with regard to number of visits and treatment progress as assessed by the therapist. Part Two of this study focuses on the evaluative capacity of the self and informant, pre and post treatment, PARS Scale ratings and relates these to number of treatment sessions and therapist behavioral assessment. In addition, Part Two of the study focuses on changes in client behavior after three months of treatment as measured by the PARS Scale, pre and post treatment ratings. 
Nul1 Hypotheses for Parts One and Two of Study

The null hypotheses for Part One of the present study are stated:

1. In the female population, the number of treatment sessions will not be related to the self pre treatment PARS Scale ratings on Interpersonal Involvement, Agitation-Depression, Attention-Confusion, Alcohol-Drug, Outside Social, and Household Management factors.

2. In the male population, the number of treatment sessions will not be related to the self pre treatment PARS Scale ratings on Interpersonal Involvement, Agitation-Depression, Attention-Confusion, Alcohol-Drug, Outside Social, and Anxiety factors.

3. In the female population, therapist assessment of progress in therapy will not be related to the self pre treatment PARS Scale ratings on Interpersonal Involvement, Agitation-Depression, AttentionConfusion, Alcohol-Drug, Outside Social, and Household Management factors.

4. In the male population, therapist assessment of progress in therapy will not be related to the self pre treatment PARS Scale ratings on Interpersonal Involvement, Agitation-Depression, AttentionConfusion, Alcohol-Drug, Outside Social, and Anxiety factors.

The null hypotheses for Part Two of the present study are stated:

1. For females there will be no significant differences after three months of treatment between the self pre and post treatment PARS Scale ratings on the Interpersonal Involvement, Agitation-Depression, 
Attention-Confusion, Alcohol-Drug, Outside Social, and Household Management factors.

2. For females, there will be no significant differences after three months of treatment between the informant pre and post treatment PARS Scale ratings on the Attention-Confusion, Alcohol-Drug, and Outside Social factors.

3. For females, the number of treatment sessions will not be related to the self pre treatment PARS Scale ratings on Interpersonal Involvement, Agitation-Depression, Attention-Confusion, Alcohol-Drug, Outside Social, and Household Management factors.

4. For females, the number of treatment sessions will not be related to the self post treatment PARS Scale ratings on Interpersonal Involvement, Agitation-Depression, Attention-Confusion, Alcohol-Drug, Outside Social, and Household Management factors.

5. For females, the number of treatment sessions will not be related to the informant pre treatment PARS Scale ratings on Interpersonal Involvement, Agitation-Depression, Attention-Confusion, Alcohol-Drug, and Outside Social factors.

6. For females, the number of treatment sessions will not be related to the informant post treatment PARS Scale rating on the Alcohol-Drug factor.

7. For females, therapist behavioral assessment will not be related to self pre treatment PARS Scale ratings on Interpersonal Involvement, Agitation-Depression, Attention-Confusion, Alcohol-Drug, Outside Social, and Household Management factors. 
8. For females, therapist behavioral assessment will not be related to self post treatment PARS Scale ratings on Interpersonal Involvement, Agitation-Depression, Attention-Confusion, AlcoholDrug, Outside Social, and Household Management factors.

9. For females, therapist behavioral assessment will not be related to informant pre treatment PARS Scale ratings on Interpersonal Involvement, Agitation-Depression, Attention-Confusion, Alcohol-Drug, and Outside Social factors.

10. For females, therapist behavioral assessment will not be related to the informant post treatment PARS scale rating on the Alcohol-Drug factor.

\section{LIMITATIONS OF STUDY}

There are some notable limitations with regard to the present study. The random sample is not identified by demographic characteristics or presenting problem and the non random sample is not identified by presenting problem. Neither Parts one nor Two of this study specify therapist characteristics or specific treatment characteristics. There is no "control group" nor alternate treatment group for comparison in either Parts One or Two of this study. Finally, there is a notable lack of data on informant post treatment PARS Scale factors ratings in Part Two of the present study. 
V. SUMMARY

The present study is a preliminary effort to explore the predictive and evaluative capacity of the PARS Scale in assessing continuation in treatment and treatment outcome for evaluation of treatment services.

The study was conducted with evaluative data provided by a community mental health clinic in an essentially low-income catchment area.

Part One of the study pertains to an exploration of the predictive capacity of the PARS Scale (self pre treatment form) with regard to continuation in treatment and treatment outcome as they relate to the number of treatment sessions and the therapist assessment of progress in therapy.

Part Two of the present study focuses on treatment outcome and the evaluative capacity of the PARS Scale through measurement of change after three months of treatment on self pre and post treatment PARS Scale ratings and informant pre and post treatment PARS Scale ratings and by therapist behavioral assessment at three months. Part Two of the present study also explores continuation in treatment through number of treatment sessions and their relationship to therapist behavioral assessment, and self and informant pre and post treatment PARS Scale ratings.

Finally, both Parts One and Two of the present study explore an unrefined investigation of the kinds of termination implemented by the samples under study. 
CHAPTER II

REVIEW OF THE LITERATURE

Research in psychotherapy has been' and continues to be a controversial area of study, especially with regard to outcome studies. This concern is reflected across professions associated with psychotherapy research (Ford, 1972; Geismar, 1972; Volsky, Magoon, Norman, and Hoyt, 1965).

The review of the literature will attempt to reflect the status of relatively recent psychotherapy research, studies conducted between 1953 and 1973. The first section will present a brief overview of some of the more prominent difficulties in psychotherapy research. A second section will consider research regarding factors associated with continuation in therapy and is related to the first part of this study. The third section will present research on factors associated with outcome in psychotherapy and pertains to the second part of this study. A concluding section will attempt to summarize concisely the efforts of this chapter.

\section{PROMINENT ISSUES IN PSYCHOTHERAPY RESEARCH}

Although research in psychotherapy began prior to Eysenck's (1952) study, much of the research has been done subsequent to it and some of it in response to it. Eysenck's review (1952) of treated 
and untreated samples evidenced no significant differences in outcome, leading him to conclude from his data that, "They fail to prove that psychotherapy, Freudian or otherwise, facilitates the recovery of the neurotic patient" (p. 323). Researchers have attempted to respond to the challenge that the burden of proof lies with those who espouse belief in the benefits of psychotherapy. Nevertheless, research frequently has appeared ambiguous and, consequently, subject to individual interpretation, as demonstrated by Bergin (1971). However, there appears to be evidence that some of the factors that have contributed to previous question of the benefits of psychotherapy are open to re-evaluation and clarification (Bergin, 1971). The more prominent of these factors are spontaneous remission and control groups, deterioration rates, and methodology.

\section{Spontaneous Remission, Placebos, and Control Groups}

In the twenty years following Eysenck's original study, the use of control groups, placebo effects, and spontaneous remission rates has been further investigated, leading to some skepticism regarding Eysenck's (1952) high rate of spontaneous remission. Bergin (1971), after reviewing a number of notable studies, concludes that, while yet in need of further investigation, the probable rate of spontaneous remission lies somewhere between $15 \%$ and $45 \%$, dependent upon the diagnostic category of the disorder under study.

Therapist "warmth" has been repeatedly identified by patients in follow-up studies as an essential therapist quality (Feifel and 
Eells, 1963; Goldstein, 1962; Strupp, Fox, and Lessler, 1969). Truax and Carkhuff (1967) have shown that this quality, along with other identified essential therapist qualities, occurs in the "natural" environment. In addition, and while still in need of further investigation, "psychological" placebos have been demonstrated to have therapeutic value (Goldstein, 1962). Thus, it is unlikely that any "pure" control group is possible, or that any totally "spontaneous" remission occurs. While these qualities are undoubtedly included in "good" therapy, they are not necessarily nonexistent in the natural environment. Goldstein (1960) has suggested the term "nonspecific therapy remission."

It is presently the goal of the researcher to identify the characteristics in "non-specific therapy remission" and placebos, so that "control" groups can be utilized more effectively in research and the curative qualities of these phenomena can be utilized in therapy (Goldstein, 1962).

Deleterious Effects of Psychotherapy

In recent research, another phenomenon that has received some attention is the deleterious effects of psychotherapeutic intervention. There has been noted in some experimental groups a variability in post-therapy outcome results that does not seem to appear in control groups (Fischer, 1973; Truax and Carkhuff, 1967; Volsky, Magoon, Norman, and Hoyt, 1965). This range of outcome scores has led some researchers to suggest that psychotherapy can be harmful as well as beneficial and that this, in part, can account for some of 
the negative or minimized results in outcome research where therapist and process are not controlled (Bergin, 1971; Grey and Dermody, 1972). Malan (1973) in a recent "review of reviews" states regarding future research:

\footnotetext{
- . there will be many negative findings; because I am also convinced that what analysts have never faced up to is that there are many types of patient, whom we continue to treat with never-diminishing hope and everincreasing denial, who are not helped by our methods. It has been the failure to face this that has for so long stood in the way of our showing that, with other types of patient, our work may be uniquely effective. The definition of the populations and techniques for which this is true is what we must reach in the next few decades ( $p .728$ ).
}

\section{Methodology}

Finally, and perhaps most importantly, methodology in psychotherapy research has been severely criticized and viewed as a major source of difficulty in securing clear outcome studies. Herzog (1959) fifteen years ago stated in a government published handbook:

Apparently, the most satisfactory basis for judging whether the findings of an evaluative study are "good" or "bad" is beyond us until we are able to make dependable comparisons between methods of treatment, kind of therapy, performance of different agencies or practitioners, and treatment and notreatment ( $\mathrm{p} .72$ ).

Recent emphasis has been placed on securing this kind of specificity with regard to patient, therapist, process, and outcome variables. It is thought that specificity would reduce the use of heterogeneous variables interchangeably, as though they were homogeneous, and provide more definitive results with regard to patient, therapist, treatment, and outcome. This, in turn, would allow for increased comparability of studies and reduced ambiguity in 
interpretation of results. This refinement in research procedure is encouraged by both researchers and therapists, for both clarification of assessment and modification and development of theory and therapeutic procedure (Breedlove, 1972; Perlman, 1971; Bergin and Strupp, 1972). Hans Strupp (Bergin and Strupp, 1972) summarizes this emphasis:

Accordingly, he (the therapist) must succeed in defining "the problem" (that is the patient state to be modified), the kinds of personality and behavior changes to be achieved, and the procedure to be employed in reaching them. In short, the therapist and the researcher must become increasingly EXPLICIT ABOUT THE OPERATIONS OF PSYCHOTHERAPY AND THE NATURE OF THE THERAPIST'S INFLUENCE. Existing knowledge, while undoubtedly embodying important psychological principles, is altogether too general, broad-gauged, and imprecise. I conclude that future research in this area must firmly rest on empirical data; and specificity; and it must seek to isolate psychological principles embedded in, and of ten obscured by, divergent theoretical formulations (p. 436).

Any degree of precision in this effort, considering the multitude of variables at hand, will require considerable effort and coordination of effort.

\section{CLIENT VARIABLES AND CONTINUATION IN PSYCHOTHERAPY}

Most research regarding outcome in psychotherapy assumes a certain amount of contact between the client and the therapist. Many studies have shown a positive relationship between length of stay in therapy and outcome (Bailey, Warshaw, Eichler, 1959; Imber, Frank, Gliedman, Nash, and Stone, 1957). This is explored in greater detail in Section III, Subsection One of this chapter. 
Nevertheless, one of the continuing difficulties encountered in clinical practice is premature termination of therapy. Some research has attempted to investigate this problem. Garfield (1971), in a review of research in this area, points out that a number of clinics evidence losses of about half of their clients in the first three to twelve interviews and that, where clients who have refused treatment are excluded, the median number of interviews is approximately 5.5 . Ripple (1964), in a study of casework and client and therapist variables, found that favorable and unfavorable outcome could be predicted by the fourth interview. Haddock and Mensh (1957), in a study of premature terminators, found that most terminators did not plan termination but, rather, failed to return for scheduled appointments. In addition, Riess and Brandt (1965), exploring this further, have shown that the terminators in their study rarely sought therapy elsewhere.

In exploring continuation in therapy and client variables, studies have been conducted with regard to a broad range of variables. The influence of personality variables, intelligence, education, social class, and patient expectations, among other factors, have been investigated with regard to duration of therapy.

\section{Personality Variables}

One of the most complex areas of exploration has been the attempt to relate personality variables to continuation in psychotherapy. As with outcome studies in general, this has been difficult, and evidence has sometimes been conflicting, since research attempts 
have not been specific with regard to client, process, and therapist variables. In addition, terminators and remainers have been defined differently in various studies. Nevertheless, some similarities of continuers and terminators appear to emerge across studies (Luborsky, Auerbach, Chandler, Cohen, and Bachrach, 1971).

Taulbee (1958) conducted a study of 48 terminators, 45 remainers, and 50 controls who were administered the Rorschach and the MMPI. In this study terminators were defined as those terminating prior to the thirteenth interview. This study found remainers to be less defensive, more persistent, more anxious, more sensitive, and more dependent than terminators and to possess feelings of inadequacy, inferiority, and depression. In addition, remainers were found to evidence greater potential for self-appraisal, emotional responsiveness, and introspection. In comparison with the control group, this study found the remainers to resemble more closely the controls on the Rorschach.

Sullivan, Miller, and Smelser (1958), in another study, found no differentiation between terminators and remainers on MMPI data. This study defined terminators as those terminating therapy prior to the ninth interview. In this study, 268 male patients from a Veterans Administration Mental Hygiene Clinic were rated on demographic characteristics, MMPI data, and therapist assessment. While MMPI data evidenced no differentiation, the demographic data was found to distinguish terminators from remainers. 
In another study, Rubenstein, and Lorr (1956) secured data on personality variables of 128 veterans from nine Veterans Administration clinics across the country. The sample was divided into remainers and terminators, with terminators being defined as those seen for five interviews or less and remainers being defined as those remaining in treatment for at least six months. These clients were rated on the basis of a personality inventory, a self-rating scale, a vocabulary test, a modification of the Adorno-Levinson F Scale, and on socioeconomic data. Results found remainers to be less impulsive, less rigid in personal attitudes, and more self-dissatisfied than terminators.

In a similar study by Lorr, Katz, and Rubenstein (1958), 300 patients from Veterans Administration Clinics across the country were studied with measures from a behavior disturbance scale, the Taylor Manifest Anxiety Scale, a vocabulary test, and a modification of the Adorno F Scale. Terminators were defined as those discontinuing treatment prior to six weeks of therapy and remainers as those receiving treatment for six months or more. In this study, it was found again that remainers tended to be more anxious, more self-dissatisfied, and more willing to explore personal problems with others. In addition, they, unlike terminators, were less likely to have a history of antisocial acts and appeared to be more controlled, dependable, and persistent than terminators. This study was subsequently crossvalidated with a more recent Veterans Administration client sample, with similar results (McNair, Lorr, Callahan, 1963). 
Intelligence, Education, and Social Class

In addition to attempts to secure personality characteristics of the terminator and remainer, other studies have attempted to explore the relationship of intelligence, education, and social class, among other test and non-test variables, and their association with duration of therapy.

Hiler (1958), in an attempt to relate intelligence and duration of therapy, studied 133 clients in a Michigan Veterans Administration Clinic. Terminators were defined as those who left therapy within five sessions. Utilizing the Wechsler-Bellevue Scale, he found that remainers scored significantly higher on this scale. In addition, with overall intelligence held constant, remainers did significantly better on the similarities subtest, and relatively poorer on the digit symbol and digit span subtests. Hiler inferred from the latter two findings, respectively, that remainers might have greater ability to perceive relationships and insights, and that they were more likely to have emotional disturbances manifested in a greater degree of anxiety. Although not of major focus in the research, other studies have shown a positive correlation between length of stay in therapy and intelligence (Affleck and Mednick, 1959; Auld and Eron, 1953). In conjunction with this same focus of investigative research, education and duration of therapy have been positively correlated in a number of instances. Bailey, Warshaw, and Eichler (1959) found length of stay in therapy to be significantly related to the number of years of schooling of the client. Length of stay in therapy for 
purposes of this study was rated on a continuous scale: two months or less, three to six months, seven to eleven months, and twelve months or more. Rubenstein, and Lorr (1956), in a study previously cited, found that remainers tended to evidence higher educational levels. Other studies, as well, tend to support these findings (McNair, Lorr, and Callahan, 1963; Sullivan, Miller, and Smelser, 1958).

Closely interrelated with intelligence and educational level, socioeconomic status has been shown to be positively. correlated with length of stay in therapy. Imber, Nash, and Stone (1955) studied sixty patients at the Henry Phipps Psychiatric Clinic and rated them on the Warner Index of Status Characteristics. They found that middle class patients remained in treatment significantly longer than lower class patients. This held true under conditions in which training and experience of therapists was held constant and where therapists were not free to select clients or terminate them readily. In this study, approximately $57 \%$ of lower class patients stayed beyond the fourth interview, whereas $89 \%$ of the middle class patients tended to do so. In another study, Cole, Branch, and Allison (1962) found that, based on the same index, about $12 \%$ of the two lowest socioeconomic groups remained in treatment for more than 30 interviews, whereas $42 \%$ of the highest social class groups did so.

\section{Patient Expectations}

A notable area of research with regard to duration of therapy is its relationship to patient expectations of the therapeutic process and the possible implications for therapeutic procedure. 
Heine and Trosman (1960) studied 45 patients by means of questionnaire and found that terminators tended to emphasize passive cooperation as a means of reaching their goal in treatment and tended to seek medication and diagnostic information. The remainers tended to emphasize active collaboration and advice or help in changing their behavior. Both remainers and terminators were found to be hopeful about their psychiatric treatment, but remainers tended to conceptualize the experience in a manner more congruent with that of the therapist. Thus, the significant variable was that of mutuality of expectation between therapist and patient. Goldstein (1962), in his inclusive work on patient-therapist expectancies, was led to similar conclusions.

Overall and Aranson (1962), dealing exclusively with lower class patients, found similar results. In a study of 40 lower class patients by means of a questionnaire which was administered prior to and following the initial interview, they tended to confirm the aforementioned outcomes. Results indicated that these patients tended to expect a "medical-psychiatric" interview, with the therapist taking an active-supportive role, and that those patients whose expectations were most inaccurate were significantly less likely to return to treatment. In addition, they found that patients' evaluations were better predictors of return than those of therapists'.

In conjunction with these studies, some exploration has been undertaken with regard to alteration of client expectations of the therapeutic process. Goldstein (1962) has recommended "socialization" 
of the client to promote his functioning within the definitions provided by therapists and institutions. Truax and Carkhuff (1967) have done some investigation of pretraining of clients with tapes depicting "good" therapy behavior. Their "vicarious therapy pretraining" has been supported in several of their studies, although it was found to be unsuccessful in another with delinquents (Truax and Carkhuff, 1967, p. 363).

$\underline{\text { Summary }}$

It would appear that, in spite of research difficulties and conflicting outcomes, suggested patterns emerge with regard to client variables and continuation in therapy.

While some beginning research has shown the possibility that premature termination can be altered by utilization of "therapy pretraining," research indicates that about half of the client population tends to self-terminate prior to the fifth interview and does not seek formal therapy elsewhere.

While conflicts exist with regard to results, the characteristics of the terminator and remainer have tended to show some differentiation across studies (Luborsky, Auerbach, Chandler, Cohen, and Bachrach, 1971). Levinger (1960) in a review of research associated with continuation in therapy offers a summarization of the continuer's personal attributes:

Regarding $\mathrm{P}^{\prime} \mathrm{s}$ [Patient's] personal attributes, continuers generally have greater discomfort, are more prone to see themselves responsible for their problems, and show higher motivation in trying to solve these and other kinds of problems. Moreover, continuers show greater ability to respond to the 
helping person and a greater willingness to explore their problems. Finally, in the treatment of adults, middle-class persons are more likely to continue than are lower-class persons . . (p. 49).

In brief, it would appear that research tends to indicate that the client most likely to remain in treatment: will remain, at least, beyond the fifth interview; appears better adjusted, although expressing greater dissatisfaction; tends to be in the upper strata with regard to education, intelligence, and socioeconomic advantages; and, finally, is more cognizant of the therapeutic process.

\section{OUTCOME STUDIES AND RELATED VARIABLES}

Overall outcome studies have increased in numbers in the past ten years, but tend to possess limitations similar to those studies conducted prior to the last ten years.

Bergin (1971), in his review, regards outcome studies as "inconclusive" or indicative of "modestly positive results." He notes in his review that outcome studies tend to be conducted without control groups, and generally without specification of the nature of therapy, and in total tend to indicate only the "gross effects" of therapeutic intervention.

Kellner (1967) criticized outcome studies in his review noting that results were often conflicting; comparability of studies was absent; and divergent processes were simultaneously included under the intervening variable, "psychotherapy." Nevertheless, he noted some consistencies in outcomes in spite of these limitations. 
Luborsky, Auerbach, Chandler, Cohen, and Bachrach (1971), in another review of outcome studies, arrived at similar conclusions. They reviewed a series of quantitative studies, conducted from 1946 to 1969 , that researched factors influencing the outcome of individual psychotherapy. They included only those studies in which they ascertained that,". . there was at least some attempt to provide reasonably controlled comparisons, and conclusions were passably supported" (p. 146). They note, in summarizing the limitations of these studies, that they are based on diverse groups of patients in type and initial severity of illness, and that, in addition, they are based primarily on treatment classified as "short-term." Furthermore, they point out that, in nearly all of the studies they reviewed, no control over knowledge of "counsel," other than therapy, existed and that the quality and type of this therapy was not controlled. Finally, they note that the outcomes of their review might be biased by the propensity of editors to publish studies reflecting positive outcomes. Nevertheless, they, too, tend to observe suggestive consistencies across studies.

Strupp and Bergin (1969), in an inclusive review of psychotherapy research, advocate specificity in outcome studies, indices which measure both internal and external states, and assessment designed for individual clients or groups of clients.

Subject to these limitations, outcome studies have explored the effects of psychotherapy with regard to multiple factors and have produced both divergencies and consistencies in results. 
Duration of Therapy and Treatment Outcome

As previously noted, outcome research in psychotherapy assumes a certain amount of contact between the client and the therapist, and some research has been done regarding this.

Imber, Frank, Nash, Stone, and Gliedman (1957) found that, "Patients having fewer and briefer sessions of psychotherapy will show significantly less improvement than patients with more and longer sessions over the same period of $t^{\prime \prime m e}$ (p. 315). In this study of 54 psychiatric patients, those receiving restricted therapeutic contact showed less improvement as rated by a psychologistobserver, a therapist, and a significant other, both prior to and following six-month contact.

Bailey, Warshaw, and Eichler (1959), in a study of 247 psychosomatic patients and 211 psychotherapy patients from a mental hygiene clinic, found a "highly significant" relationship between length of stay in therapy and treatment outcome as assessed by therapist evaluation.

In contrast, Lorr, McNair, Michaux, and Raskin (1962) found, in a study of 133 Veterans Administration outpatients, that changes in the predicted directions did not increase with the frequency of interviews at four months or eight months. However, these researchers did find that increased length of stay in therapy tended to produce increased changes as measured by ten objective scales and, in addition, tended to maintain them one year after termination. 
Finally, Garfield (1962), in a small study of eleven terminators, who relinquished treatment at seven interviews, found that, by self-report, the terminators were adjusting as well as the remainers.

Thus, support would appear to favor frequency and duration of therapeutic contact but, as can be observed, the small sample of studies cited is not comparable.

\section{Patient Expectancies and Outcome Studies}

Another area of research with regard to outcome that is of note is the exploration of patient expectancies and their influence on therapeutic outcome.

Goldstein (1960) found a significant correlation between patients' expected and perceived improvement, as assessed prior to and following initial interview.

Goldstein and Shipman (1961), in another study, found, following initial interview, a positive but curvilinear relationship between expectancy and perceived symptom reduction. Goldstein (1962), in a subsequent and inclusive review, concluded that of all patient expectancies, those pertaining to prognosis evidenced the most significance in a positive but curvilinear relationship.

By contrast, Friedman (1963) found that a positive and linear relationship existed between patient expectancies and symptom reduction, following initial interview, and especially with regard to anxiety and depression.

Thus, it would appear from this research that the patient with a positive, but realistic, anticipation of improvement will have 
greater success in therapy, although Friedman's study indicates that the patient needs only a positive anticipation of improvement.

Personality Variables, Adjustment Factors, and Outcome

Diverse attempts have been made to assess personality variables and adjustment factors and their relationship to outcome in psychotherapy. These oftentimes have appeared to be inconclusive and conflicting, in part, for reasons discussed at the beginning of this section. Garfield (1971) comments in this regard:

The problem of what kinds of clients or personality attributes of clients are related to outcome in psychotherapy is clearly a complex one that does not appear to be readily answerable by single small-scale investigations ( $p .292$ ).

Nevertheless, some researchers have observed some consistencies across outcomes (Kellner, 1967; Luborsky, Auerbach, Chandler, Cohen, and Bachrach, 1971; Strupp, and Bergin, 1969).

In this research attempt, various standardized instruments have been employed, as well as self-designed measures. Rosenberg (1954) employed the Rorschach, the Wechsler-Bellevue, and a sentencecompletion test in the study of 40 male patients of a Veterans Administration Mental Hygiene Clinic. The patients were divided into "improved" and "unimproved" categories by therapist assessment after nine months of therapy. The successful patient was found to be able to produce associations easily, be of superior intelligence, lack rigidity, hold a wide range of interests, feel deeply, exhibit sensitivity to his environment, evidence a high energy level, and be relatively free from somatic symptoms. 
By way of contrast, Rogers and Hammond (1953), in a previous study, found the Rorschach, of itself, unable to distinguish between "improved" and "unimproved" patients.

Barron (1953), again utilizing the Rorschach and the WechslerBellevue and including the MMPI, found no distinction between "improved" and "unimproved" on the Rorschach, although distinctions were made on the Wechsler-Bellevue and the MMPI. "Unimproved" patients showed higher scores on the Paranoid and Schizophrenia Scales of the MMPI. Barron was led to conclude that: "The patients who are most likely to improve are not very sick in the first place" (p. 240)

Sullivan (1958), in his study of 268 Veteran outpatients, was led to similar conclusions, with the less pathological, as assessed by the MMPI, evidencing the greatest improvement in therapy . Similarly, Luborsky, Auerbach, Chandler, Cohen, and Bachrach (1971), in their recent review of outcome studies, conclude:

Of the 28 studies that fall within this category [Adequacy of General Personality Functioning], 15 show a significant relationship between the level of initial personality functioning and outcome of treatment; of these 14 are in the positive direction. They indicate that the healthier the patient is to begin with, the better the outcome--or the converse--the sicker he is to begin with, the poorer the outcome (pp. 147-48). In addition, they note that some improvement is shown by patients, whatever the initial level of functioning. They indicate that most of these studies included therapist assessments for evaluation purposes and point out that this is the most frequently used criterion measure in the studies cited. Furthermore, they state that they 
find it to be". . the only criterion measure which tends to have consistent significant correlations with other criterion measures" (p. 158).

Considering this observation by Luborsky and his colleagues, it is important to include the conclusions of a study by Mintz (1972) on therapist and untrained observer evaluations of patients. Mintz observes:

The final level of functioning achieved is of key importance in global evaluation of treatment outcome. In general, the better adjusted the patient at the end of therapy, the better the outcome rating, regardless of the amount of change involved. Since patients beginning therapy with relatively good adjustments are likely to end therapy with relatively good adjustments, they are likely to obtain high outcome ratings though they change relatively little ( $p .18$ ).

He notes further:

In short, more severely troubled clients tend to change more (at least in psychometric terms); less disturbed clients tend to end treatment better adjusted. The researcher should be aware that people, whether clinically trained or untrained, tend to value the latter result more ( $p, 18)$.

The observations of Mintz (1972) and Luborsky et a1. (1971) tend to indicate different possible observations regarding the conclusion that it is the healthier client who is more successful in therapy. Mintz's study suggests that this finding may result, at least in part, from the tendency of therapists (and significant observers) to regard an ultimate high level of adjustment as indicative of greater improvement in therapy, regardless of real improvement. Luborsky et al., however, find that therapist evaluations are the only measure consistently correlated with other measures of adjustment, seemingly lending support to this means of assessing therapy outcome. 
By way of contrasting exploration, Truax and Carkhuff (1964), in a study of controls and therapy patients, found that the patients evidencing the greatest internal disturbance, as indicated by MMPI and Q-sort measures, and the lowest external disturbance, as indicated by the Wittenborn Psychiatric Rating Scales, were those showing greatest improvement in therapy. These findings were confirmed by additional studies (Truax and Carkhuff, 1967, pp. 169-174). They postulated the tentative conclusion as a result:

- . it seems likely that a HIGH LEVEL OF "FELT" DISTURBANCE (as measured by self-report questionnaires of felt anxiety, etc.) and a LOW LEVEL OF "OVERT" DISTURBANCE (as measured by ward behavior ratings, length of institutionalization, current college grades, etc.) ARE MOST PREDICTIVE OF OUTCOME (p. 17.4).

Similarly, Strupp, Fox, and Lessler (1969), in a study of private patients by questionnaire, found the successful patient to be "less incapacitated by his difficulties" and "more disturbed at the time of his first clinic contact" (pp. 115-116).

In considering internal and external measures of adjustment, Block's (1955) study is of note. His study of college students, assessed by MMPI Scales and Q-sort, showed a curvilinear relationship between self-satisfaction and social adjustment, with either extremes on the self-satisfaction measures indicative of social maladjustment. Strupp and Bergin (1969), in a recent review of psychotherapy research, cite other patient variables which they consider to be "presently most valid." They cite "openness to influence," "patient relatability," "patient attractiveness," and "patient-therapist similarity and pairing." "Openness to influence," in their review, is 
characterized by willingness to express feelings, liking for the therapist and the therapeutic process, having and experiencing strong dependency needs, experiencing guilt and anxiety, sensing personal responsibility for problems, wanting help, and avoiding a physiological focus on problems.

Strupp and Bergin (1969) cite patient "relatability" as one of their "valid" patient variables. In this regard, Isaacs and Haggard (1966) found in their study that clients evidencing "relatability," the potential for object relations as assessed on the TAT, showed greater improvement in client-centered therapy.

Strupp and Bergin (1969) cite two other "presently valid" variables, "patient attractiveness" and "patient-therapist similarity and pairing." They cite research that has tended to show that the therapist's liking of patient and the compatability of therapist and patients' personalities are positively correlated with successful outcome.

With regard to patient-therapist pairing, as well as client need, Lerner and Cartwright (1963) studied 14 male and 14 female clients in client-centered counseling and evaluated them with scales from the Kelly Role Construct Reperatory Test. They found that the patient's initial need to change was directly related to improvement in therapy, as was the therapist's final level of understanding of the patient. Specifically, they found two significant success groups in client-therapist pairing; same-sex patients of experienced therapists whose distance from him the therapist initially reduced, and 
opposite-sex patients of inexperienced therapists whose distance from him the therapist initially increased. Their interpretation of their findings is of interest. They hypothesize that where both client and therapist feel less threat, the client can communicate relevant material more easily and the therapist can receive it more easily. They suggest that this is a result of the therapist's need to be comfortable with his similarity to the client. Thus, sex differences between therapist and client are helpful to the inexperienced therapist because he is not so closely identified with his client and they are not of consequence to the experienced therapist because identification with the client is not threatening to him.

Finally, Fulkerson and Barry (1961), in their study, found positive correlations between non-test variables, associated with adjustment, and outcome, among them, severity of illness, duration of illness, and acuteness of onset.

The research on personality variables and adjustment factors does tend to reveal the multitude of variables that have been explored with regard to outcome and, as well, reflects both the consistencies and inconsistencies of findings which will be discussed more completely in the summary of this section.

\section{General Assessments of Psychotherapy Outcome}

Some studies have attempted overall assessments of psychotherapy outcome, primarily through the use of questionnaires following termination, and have provided some gross evaluations of the therapeutic experience that appear to reflect some similarities. 
Feifel and Eells (1963) surveyed 63 patients and 28 therapists at termination with an open-end questionnaire. The patients consisted of a primarily male sample from a Veterans Administration outpatient clinic. They found that therapists tended to stress changed in symptomatic relief and improvement in social relationships in their assessments, whereas clients tended to focus on selfunderstanding and self-confidence as a result of treatment. Therapists, in assessment of method, tended to highlight technique, and clients tended to focus on the "human" characteristics of the therapist in the relationship.

Strupp, Wallach, and Wogan (1964) surveyed 11 therapists and 44 private patients with regard to therapy outcome. They state that they ". . . demonstrated the existence of substantial retrospective consensus between patients and therapists concerning essential aspects and outcome of the therapeutic experience" (p. 36). In this study they found, however, that patients tended to emphasize mastery of problems in assessing therapeutic outcome and that therapist "warmth" emerged as a significant factor in the patients' assessment of the therapeutic relationship.

Strupp, Fox, and Lessler (1969) explored this further in a more extensive study of patient response to psychotherapy. In their final study they assessed 89 patients of an outpatient clinic one year after termination. They viewed these clients as similar to those of private practitioners with the exception of financial resources. Their data tended to show, again, patient emphasis on the 
"warmth" factor in the therapeutic relationship. However, in this study, patient emphasis on improvement in interpersonal relationships and increase in self-esteem superceded mastery of problems as the primary benefit of psychotherapy. In summary, their results showed that $67 \%$ of the patients in this study reported "marked improvement." Before concluding this subsection, another study by McNair, Lorr, Roth and Boyd (1964) can be mentioned. This study, unlike the previous, employed objective tests in assessment, as well as therapist ratings. In this study 81 psychiatric outpatients from a veteran population were seen in therapy for four months. At follow-up they evidenced significantly less anxiety, hostility, and dependency. In addition, they showed greater self-acceptance and decrease of symptoms. No relapse was found one year after termination and additional reduction of anxiety was found three years after termination.

It would appear from overall questionnaire assessment that both therapists and patients agree about general improvement after therapeutic intervention, although there is some disagreement with regard to the specific sort of improvement and the process factors that account for it. One study, employing objective measures, tends to support client-therapist agreement regarding outcome.

\section{Summary}

As suggested at the outset of this section, research regarding outcome has been related to multiple and diverse variables and has reflected both consistencies and inconsistencies in terms of results. Nevertheless, there appears to be some tentative observations that can be made with regard to outcome studies, as related in this review. 
Observations regarding the factors discussed in the first two subsections seem to reflect greater clarity than those of the subsequent subsection. It would seem, from the research cited, that increase in both frequency and duration of client-therapist contact is reflected in more positive outcomes. In addition, it would appear, from the studies related, that the patient who expects success in therapeutic outcome receives it, providing his expectations are not unrealistic. Nevertheless, research was cited that would allow some question of these suppositions.

Observations with regard to personality factors and patients' adjustment reflect much less clarity. This is even more impressive when considering the plethora of research conducted and the multitude of factors included in it, most of which has not been cited specifically in this review. However, it would seem that some tentative similarities across studies can be observed.

In most instances, the research and reviews cited indicate that it is the better adjusted patient who has greater success in therapy. However, this conclusion appears to be open to some question and clarification. As Luborsky et al. (1971) note, most of their reviewed studies included therapist assessment. While they most frequently found this criterion to be correlated significantly with other indices, Mintz (1972) has observed that trained and untrained observers tend to reflect the final level of adjustment, rather than the amount of change in adjustment. 
Approaching this differently, Truax and Carkhuff (1967) have suggested that it is those clients with increased "felt" disturbance and decreased "overt" disturbance who show greatest improvement in therapy. They cite the MMPI as a measure of "felt" disturbance. While their studies (Truax and Carkhuff, 1964; Truax and Carkhuff, 1967) have supported their observations, others have not. Earlier studies by Barron (1953) and Sullivan et al. (1958) utilized the MMPI and found those patients exhibiting the greatest disturbance, as measured on this scale, tended to show the least improvement. In addition and by way of contrast, Block's (1955) observations tend to show that extreme overrating or underrating of self-satisfaction is indicative of poor social adjustment. There may be some question with regard to equating "overt" disturbance and "poor social adjustment," however. Nevertheless, it is possible that Truax and Carkhuff's observations with regard to "felt" disturbance may be reflecting the high anxiety level and distress often found in the successful client.

Thus, it would seem that the most feasible conclusion, at this point, would be that the better adjusted client, internally and externally, is more successful in therapy. However, some clarification of Mintz's findings needs to be made and clarification of the definition of "success in psychotherapy."

Nevertheless, some specific personality and adjustment factors appear to lend themselves to greater success in psychotherapy. It appears that the highly motivated and insightful client, with good 
capacity for interpersonal relations, who does not focus on somatic difficulties, is more successful in therapy. In addition, the ability to experience feelings, anxiety, guilt, and depression, seems to contribute to successful therapeutic outcome.

Furthermore, it appears that patients whose personal traits are compatibly matched with those of the therapist tend to do better in therapy.

Luborsky et al. (1971) have summarized the foregoing in their recent review of outcome studies:

Most research conclusions have been about the patient, especially of the patient as he was BEFORE treatment: the more adequate his general personality functioning, the better his future course in psychotherapy. Similarly, the higher his intelligence and other intellectual skills, the better his future in psychotherapy. Patients most likely to succeed in treatment come highly motivated for it and expect it to help. The treatment is best begun at a time when the patient is upset and shows it by high levels of anxiety and distress and the presence of other affects such as depression. Younger patients often are more pliable and make more changes. Higher educational attainment and other social achievements probably are in part an expression of adequate general personality functioning, intelligence, and motivation. During treatment patients do better who are likeable and capable of deeply experiencing and reflecting on their experiencing ( $p$. 56).

They state further:

The match between the patient and therapist is facilitated by similarities in values, attitudes, interests, and social class. The patient's intellectual and social attainments may increase his sense of having more in common with the therapist (p. 56).

Finally, global assessment of therapeutic outcome, by questionnaire and, in one instance, by objective measurement, tends to indicate therapist-client agreement in terms of success or failure. However, there is disagreement about the specifics of the success and the helping factors in the therapeutic relationship. 
IV. SUMMARY AND IMPLICATIONS

Me thodology

As pointed out at the beginning of this chapter, psychotherapy research has been subject to significant difficulties. Among the most prominent have been its inability to employ adequate control groups and its lack of specificity with regard to definition of the variables involved in the research. With regard to the latter, researchers have sought clearer definition of patient type, treatment process, and therapist variables. Considering the complexity of each of these, confronting these difficulties is a formidable task. Nevertheless, quite recent research appears to be attempting to meet the limitations of these research problems. This can be noted from some of the studies cited. Kellner (1967) states in this regard:

In recent years evidence of the efficacy of psychotherapy has accumulated; research is passing the stage of the early crude outcome studies and is beginning to test hypotheses about the patient, the therapist, and the type of change (p. 351).

In spite of the limitations imposed by research problems, researchers have not been totally suspect of the outcomes of earlier research. Both Luborsky et al. (1971) and Kellner (1967) tend to view similarities appearing in this research as strengthened by the difficulties encountered. Kellner observes, regardless of the limitations: "There are, however, some consistent results which are important BECAUSE they have been reproduced in entirely different circumstances" (p. 351). Luborsky, while citing some of the weaknesses of the studies in his investigation, concurs: 
Most of the single studies are weak reeds because of their small sample size, small number, unreliability of measures, and brevity of treatment. Although we may sometimes be steered the wrong way because all the studies on certain predictors may be subject to the same error, in taking them together and trying to discern agreements and disagreements, some consistencies emerge which probably will stand up to further testing. IT ADDS FIBER TO A FINDING WHEN IT IS RESILIENT ENOUGH TO APPEAR IN DIFFERENT GROUPS AND BY DIFFERENT ASSESSMENT METHODS (pp. 155-156).

Findings in Continuation and Outcome Research

In reviewing the findings from both continuation research and outcome research, a similarity of characteristics between the remainer in therapy and the successful therapy patient can be observed. Luborsky et al. (1971), in reviewing both kinds of research, observed, upon concluding their summarization of the characteristics of the continuer, that: "In conclusion, many of these characteristics of remainers . . seen similar to those from our review of factors influencing outcome in psychotherapy" (p. 155). It was observed, with regard to continuation research, that the continuer remained, at least, beyond the fifth session, whereas the terminator usually ceased therapy prior to this and did not seek therapy elsewhere. In addition, it was noted that nearly half of the studied clinic populations could be classified as terminators. With regard to outcome research, it was noted that most studies cited tended to indicate that the successful client has more clienttherapist contact over a longer period of time.

Continuation research tended to indicate that the client whose expectations of the therapeutic process were fulfilled tended to 
remain in therapy. In outcome research, it was observed that the client who anticipated successful outcome usually experienced it, provided it was a realistic expectation. The latter was the more significant of the findings, regarding patient expectancies.

In both continuation and outcome research, it was found that the better adjusted client tended to remain in therapy and was more successful in terms of outcome. In both instances, the client usually experienced more distress, wanted help with his problems, and evidenced more insight into these problems. In addition, and as Luborsky et al. have pointed out, both the remainer and the successful therapy patient tend to be better educated, more intelligent, and of generally higher socioeconomic status. In addition, in outcome research, at least, the successful therapy patient was usually compatibly matched with the therapist.

Global research of outcome of therapy found therapist-client agreement with regard to success or failure, but differences with regard to the specifics of the success and the therapeutic causes of it.

Implications

It would appear from outcome and continuation research that it is the client who is more intelligent, better adjusted, and more advantaged socioeconomically, who both tends to remain in treatment and to secure better adjustment from having done so.

The findings from continuation and outcome research, then, would appear to be supportive of the findings of Hollingshead and 
Redlich (1958). In their well-known study, they suggested that it was the lowest socioeconomic groups who were in greatest need of mental health care and the least likely to receive it. This was supported in a ten-year follow-up study of Myers and Bean (1968). Thus, it would seem that, not only do those in need of mental health care seem least likely to receive it, they also seem least likely to continue in it and least likely to benefit from it. In addition, if Garfield's (1971) observations are accurate, this may include nearly half of client-clinic contacts.

Rudolph and Cumming (1962), in the study of a small city, investigated practitioners' observations with regard to helping this kind of client. They observed that:

Though many studies suggest that there is need for new skills in treating this underserviced group, this survey implies that this in itself is not enough. Until there is a way of allocating new services and new skills, the danger exists not only that they will be distributed in the way that has been described for this community, but also that,.. . the services of the most highly trained workers will tend to "heap up" on the client who is best able to do without them and therefore to be withheld, because of the frustration of unresponsiveness and slow progress, from the most gravely disordered (p. 20).

In summary, while there does appear to be some "success" with "psychotherapy," it does not appear to be, at present, with those who have most need of it. 
CHAPTER III

THE PARS SCALE: DEVELOPMENT, DESCRIPTION, AND RESEARCH STUDIES

\section{DEVELOPMENT OF THE PARS SCALE}

The Personal Adjustment and Role Skills Scale, more frequently referred to in the literature as the PARS Scale, was initially developed by Robert Ellsworth at the Roseburg, Oregon, Veterans Administration Hospital (E1lsworth, 1968).

The unique feature of this scale is the provision for assessment of behavioral changes by an informant. The informant is requested to assess the behavior of the client prior to treatment and after three months of treatment or, in the case of hospitalized patients, three months after return to the community. Ellsworth (In press) has attempted to include the informant as a "consumer" of mental health services. Whereas most studies have included only self-evaluation, it has been Ellsworth's goal to include "consumer feedback" from the informant as well.

In a study cited by Ellsworth, Carr and Whittenbaugh (1965) found that there tended to be little agreement between the patients' and therapists' assessment of improvement in therapy. In addition, Ellsworth has given consideration to Paul's (1967) findings that therapist and client assessment of outcome tends to be unreliable and lacking validity. Ellsworth (In press) appears to have 
concluded, like Paul, that the most promising criteria for treatment assessment are objective measures of behavioral change occurring in situations external to the treatment environment. In this regard, it is of interest to note that Luborsky et a1. (1971) also found that, "Where several criterion measures are available, correlations among them are usually low and often not statistically significant" (p. 158). Nevertheless, they also proceed to point out that, "The only criterion measure which tends to have consistent significant correlations with other criterion measures is the therapist's ratings of success or improvement" (Luborsky et al., p. 158).

The initial PARS Scale, PARS-I Scale, was designed for assessment of hospitalized males three months after their return to the community (E11sworth, In press). This study was conducted at the Roseburg, Oregon, Veterans Administration Hospital (E11sworth, Foster, Childers, Arthur, and Kroeker, 1968). It was anticipated that this assessment would assist in evaluation of different treatment approaches but the study was never fully completed (E11sworth, 1973; E11sworth and Ellsworth, 1970).

A second form of the PARS Scale, PARS-II Scale, was designed for the assessment of hospitalized males and females three months after their return to the community (Ellsworth, In press; Thorne and Goff, 1972). This study was conducted at Oregon State Hospital and included both self and informant pre and post assessment.

A third form of the PARS Scale, PARS-III Scale, was developed for assessment of treatment of Oregon community mental health clinic 
outpatient males and females (E1lsworth, In press). In this study the PARS Scale was redesigned to be more appropriate for the evaluation of an outpatient population. It is this PARS Scale, the PARSIII Scale, that is used in the present study.

\section{DESCRIPTION OF THE PARS-III SCALE}

The PARS-III Scale was developed out of previous PARS Scales to assess more accurately an outpatient male and female clinic population.

As with previous PARS Scales, two forms were developed: one for males and one for females. Factors were added that were more appropriate for an outpatient population and for female clients in this population. The items that best differentiated between pre and post treatment groups were factor analyzed using a principal components procedure with a verimax rotation (E11sworth, 1974). This resulted in a 90-item scale for male evaluation by an informant and an 82 -item scale for female evaluation by an informant. This then produced four different scales for informant evaluation: an informant pre treatment form for the male, an informant pre treatment form for the female, an informant post treatment form for the male, and an informant post treatment form for the female. While different forms are used, these all are similar in content with the few exceptions noted below.

The self forms for pre and post treatment assessment are the same. There is one male self PARS Scale form for both pre and post 
treatment assessment and one female self PARS Scale form for both pre and post treatment assessment. Both the male and female forms contain 57 items corresponding to the eight factors for males and females in the PARS-III Scale. These forms were adapted from the original self scale for hospitalized patients and the PARS-III Scale for the informant. The present study is the first to include pre and post self evaluation along with pre and post informant evaluation in a community mental health clinic study. The two previous studies on outpatients in Oregon community mental health clinics employed only the informant ratings.

The scales are scored according to one of two methods described in the PARS Manual (Ellsworth, 1968, pp. 9-16). Male and female forms are scored differently and scoring was intended to be designed to be done by secretarial staff. Raw scores are recorded on the PARS Scale Score Sheet (E1lsworth, 1968). This sheet provides for raw pre and post scores on each of the eight factors measured, name of the rater, relationship of the rater to the client, marital status, education, income level, number of treatment sessions, and type of mental health service received. There is a PARS Scale $\underline{\text { Score }}$ Sheet for males and one for females.

Raw scores for each scale can be mathematically converted into standard scores once the mean and standard deviation are known. The mean standard score is 50 with an accompanying standard deviation of 10. The range of scores can vary between 20 and 75 contingent upon the factor being measured. Raw scores can be plotted on the 
PARS Community Diagnostic Profile (Ellsworth, 1968). There is a separate profile for males and a separate profile for females due to the difference in the scales for both.

As with previous scales, the PARS-III Scale is divided into Personal Adjustment and Role Skills factors for both males and females. For both, the PARS-III Scale offers seven similar personal adjustment and role skills factors for assessment: Interpersonal Involvement, Agitation-Depression, Attention-Confusion, Alcohol-Drug, Outside Social, Employment, and Parent-Child Involvement. Parent-Child Involvement is optional on both the male and female scale. Employment is an optional factor on only the female scale.

Interpersonal Involvement is designed to measure the client's consideration for and interest in the informant and his or her ability to talk about important concerns and angry feelings. Agitation-Depression is designed to measure the client's fear, nervousness, restlessness, and suspiciousness. The Attention-Confusion factor is intended to measure the client's ability to keep track of time, remember important things, and lack of need for supervision. The Alcohol-Drug factor measures excessive drug or alcohol intake and its interference with family relationships. Outside Social is intended to assess attendance at and participation in activities outside the home or in-home visitation by friends and associates. Employment is intended to measure adequate employment and earnings and job satisfaction. Parent-Child Involvement is designed to measure kind and degree of parent and child interaction. 
The Anxiety factor on the PARS-III Scale appears only on the male form of this scale. It is designed to measure difficulties with eating and sleeping, nervous feelings, tenseness, and feelings of guilt and restlessness.

The Household Management factor appears only on the female form of the PARS-III Scale. It is intended to measure shopping, preparation of meals, house-cleaning, and other household chores.

Sixteen Oregon community mental health clinics participated in this study of the development of the PARS-III Scale for outpatient use. In this study the sample was composed of married couples and ratings were collected from husband and wife pairs. The males in this sample averaged 38 years of age and the females 34 years of age. Both males and females averaged 12 years of education. Data was collected on 65 pre treatment males and 64 post treatment males and 69 pre treatment females and 63 post treatment females.

In this initial study with the PARS-III Scale results showed greatest changes in female adjustment on the Agitation-Depression factor, the Attention-Confusion factor, the Household Management factor, and the Outside Social factor (E1lsworth, In press). Males evidenced greatest changes in adjustment on the Attention-Confusion factor, the Agitation-Depression factor, and the Anxiety factor (E11sworth, In press). 
III. RESEARCH RESULTS WITH THE PARS-III SCALE

Subsequently, the PARS-III Scale was used in a study of twentysix Oregon community mental health clinics in which $20 \%$ of the clinic population was sampled (Goff, Osborne, Campbel1, and Fletcher, 1971; Thorne and Goff, 1972b).

The clinic population was sampled by selecting every fifth client who met the requirements of this study. Clients had to be between 16 and 64 years of age since the PARS Scale is not appropriate for children or adolescents. In addition, the client had to attend the clinic for at least three treatment sessions. Informants in this sample were required to have resided with the client for at least one month or, in instances where the client lived alone, had to be the informant most familiar with the client's community adjustment.

In this study clients were assessed at the outset of treatment and three months after the initial interview. They were assessed by the informant only. Clients were given the PARS Scale to present to the informant or it was mailed with a return stamped envelope. In the event that it was not returned within the week, the clinic secretary made telephone contact with the informant. Where this was unsuccessful another letter followed.

Out of a total of 350 pre PARS, 186 post PARS were secured, resulting in $54 \%$ of the sample providing both pre and post informant PARS-III Scales. In this study results were tabulated in three separate clinical categories: Marriage and Family, Adult 
Psychiatric, and Child Guidance. Partial results from this study appear in Table III of Chapter V. As Goff et al. (1972) observed the sample evidences returns from approximately three times as many female clients.

The results of this study showed that female clients receiving either Marriage and Family services or Adult Psychiatric services showed improvement (Ellsworth, 1968). The male clients who received Marriage and Family services showed improvement, whereas those males receiving Adult Psychiatric services did not (Ellsworth, 1968).

A more complete analysis of the results appears in Thorne and Goff (1972b). With regard to Marriage and Family services, the 38 females showed improvement in Interpersonal Involvement, AgitationDepression, and Attention-Confusion. The 38 males in this category showed improvement in Interpersonal Involvement, Agitation-Depression, Attention-Confusion, Anxiety, and Alcohol-Drug. With regard to Adult Psychiatric services, the 29 females showed improvement in Interpersonal Involvement, Agitation-Depression, Attention-Confusion, Household Management, and Parent-Child Involvement. The 13 males in this category revealed no significant differences on any of the eight factors. With regard to Child Guidance services no improvement on any of the eight factors appeared for the 26 females. These same females observing their spouses reported positive changes in the 26 males on Interpersonal Involvement, Agitation-Depression, Anxiety, Alcohol-Drug, and Employment. Neither, however, observed improvement in the spouse on Parent-Child Involvement. Thorne and Goff 
(1972b) used the $t$ statistic for correlated means to determine significance at the .05 level and the .01 level.

While no other known studies have been done with the PARS-III Scale in Oregon community mental health clinics, the Department of Mental Hygiene in the State of California is now employing this scale in a study of community mental health clinics (Hanson, 1973). This study is attempting to assess a sample of 2000 outpatient clients within five counties at four, eight, and twelve months with the PARSIII Scale. An informant PARS-III assessment and a therapist evaluation are being used in this study, in addition to other means of treatment evaluation. No self PARS assessment is being used. Results from this study are not available for publication at this time.

\section{SUMMARY}

In conclusion, the PARS-III Scale employed in the present study is unique in that it includes assessment by an informant. In the present study both the self PARS Scale and the informant PARS-III Scale are used. Presently, this is the only comminity mental health clinic study in which the self PARS assessment has been included.

The PARS-III Scale is an instrument that has been redesigned for an outpatient community mental health clinic population and attempts to measure both personal adjustment and role skills. While different forms of the PARS and PARS-III Scale are used for males and females both include measurement of seven similar factors: 
Interpersonal Involvement, Agitation-Depression, Attention-Confusion, Alcohol-Drug, Outside Social, Employment, and Parent-Child Involvement. The male form includes an Anxiety factor and the female form a Household Management factor.

There are two studies in which the informant PARS-III Scale has been employed in Oregon community mental health clinics. These studies suggest that the scale may be able to make some indication of behavioral changes. Results from these studies indicate that for both males and females the Agitation-Depression factor is the most notable indicator of change along with the Anxiety factor for males and the Household Management factor for females. Some indication of change for both males and females seems to occur on the Interpersonal Involvement factor and the Attention-Confusion factor. In addition, for males some indication of change seems to occur on the Alcohol-Drug factor. In addition, in a few instances Employment seems to be an indicator of change for males and Parent-Child Involvement for females. Outside Social does not appear in any instance to measure change for either males or females and in no instance does Alcohol-Drug measure change for females.

Another study only with the informant PARS-III Scale is being conducted currently in California community mental. health clinics with a much larger projected sample. The results from this study are not available presently for publication. 
By way of summary it is probably advisable to adhere to the admonition of Robert Ellsworth (1968) in the PARS Manual:

However, a great deal more research will be required before we can be assured that the scores are valid indicators of change. Certainly in no case should the PARS, or any other single indicator, be used as a sole basis for determining treatment effectiveness ( $p, 5)$. 


\section{CHAPTER IV}

\section{SAMPLES AND METHODOLOGY}

This research project has been conducted in two parts and involves two different samples. In addition, while there is some overlap in methodology for the two parts, there are also differences. Therefore, both sample and methodology for each part will be discussed separately.

Part One of the present study explores the continuation in therapy of all clinic applicants who took the self pre PARS Scales. It explores their pre treatment adjustment as assessed by the self pre PARS Scale in relation to their length of stay in treatment, therapist assessment of treatment progress, and kind of termination.

Part Two of the present study explores the treatment outcome of those clinic applicants who remained in treatment for three months or more. It attempts to assess their treatment outcome in terms of their self and informant, pre and post, PARS Scale scores and the relationship of these scores to length of stay in treatment, therapist behavioral assessment, and kind of termination.

\section{DESCRIPTION OF SAMPLES}

Sample for Part One of Study

In Part One of this study a random sample of 70 clients between the ages of 16 and 64 was selected from a total population of 249 
clients applying to the clinic for services from 11-21-72 to 7-21-73. The cutoff date of 7-21-73 was selected in order to allow for at least three months of possible treatment.

The total population included only those clients who had contact with. Delaunay for at least one session. This first contact typically involved administration of the self PARS Scale and, when possible, the informant PARS Scale. If no informant was present for the initial session, a release of information form for the informant was secured in this contact.

All clients who applied to the clinic for services after 11-21-72 were administered the pre PARS Scale for the self and requested to have an informant complete the pre informant PARS Scale.

The population did not include those clients applying by telephone for treatment services and who did not appear for the initial contact. Neither did it include those clients receiving services who did not complete at least one of the eight self pre PARS Scales.

The population for the random sample of this part of the study was not distinguished by income level, education level, marital status, kind of presenting problem, or treatment method employed.

Sample for Part Two of Study

In Part Two of this study the sample was not randomly selected. The sample consisted of those clients, aged 16 to 64 , who remained in treatment for three months or more and provided both pre and post self PARS Scales and both pre and post informant PARS Scales. It is important to note that, even in this sample, post self and post informant 
PARS Scales were not always complete on all eight factors. Male post informant PÁRS Scale ratings were most notably incomplete. Again this sample was taken from applicants to the clinic between 11-21-72 and 7-21-73 in order to allow for at least three months of treatment.

Observations were noted with regard to the more prominent characteristics of this sample. Of necessity this sample remained in treatment for at least three months. Thirty-three per cent of this sample were male. Clients in this sample had, at least, a high school education and frequently some college education. Half of the clients in this sample had income levels under $\$ 3,000$, but the range extended from under $\$ 3,000$ to $\$ 10,000$ or more, and $25 \%$ of the sample had income levels at $\$ 8,000$ to $\$ 10,000$ or more. Seventy-five per cent of this sample ranged in age from 21 years of 40 years of age. Fifty per cent of the sample applied for Adult Psychiatric services and $25 \%$ for Marriage and Family services. Fifty per cent of the clients in this sample were married and the informant most frequently named was a spouse or a friend.

Again, this sample was not distinguished by kind of treatment received.

\section{METHODOLOGY}

Methodology for Part One of Study

All clients who came to the clinic between 11-21-72 and 7-21-73 were given the self pre PARS Scale at inftial contact. In addition, 
if they were not accompanied by the informant, they were requested to complete a rater consent form which included the name and address of the informant. If present, the informant completed the informant pre PARS Scale. If the informant was not present, he was then mailed the informant pre PARS Scale with a self-addressed, 'stamped envelope and a cover letter explaining the project and noting the client's permission to provide the requested information. If the initial mail contact failed to secure response from the informant, a follow-up letter was sent explaining the importance of the informant's response. Completed pre self and pre informant PARS Scales were then scored by the clinic secretary assigned to this project and according to the instructions in the PARS Manual (E11sworth, 1968, pp. 9-16). These raw scores were then tabulated on the PARS Scale Score Sheet (E11sworth, 1968) on either the male or female form. For purposes of this study, they were subsequently converted into the standard scores described in Chapter III.

Subsequently, continuation in therapy was determined by the number of visits to the clinic for the random sample. These were secured from the billing cards. No distinctions were made with regard to kind of treatment: individual therapy, group therapy, and/or family therapy. However, in the event the client was hospitalized, therapist visits to the hospital were omitted. Number of visits was counted only in the three-month period following the initial interview in order to equalize the time differential for clients initially seen in November of 1972 and those seen in July of 1973. This allowed 
for only three months of clinic contact regardless of when the client applied for treatment and did not give advantage of additional time to those clients applying for treatment early in the study.

In October of 1973, therapists at Delaunay Institute were requested to provide information on the random sample with regard to kind of termination, progress in therapy, and therapist certainty in assessing progress. It is important to note that this information could have been requested on a client seen only for initial interview a year earlier, making accurate assessment in these cases most difficult. In addition, some of these clients could conceivably have been seen by a psychology intern or a social work trainee, making assessment even more difficult. Where possible, however, the intern or trainee was contacted and requested to make the assessment himself or herself.

Kind of termination was determined by therapist response to the Termination Checklist, as shown in the Appendix. Five kinds of termination were possible: client terminated, client-therapist terminated, therapist terminated (client referred), therapist terminated (client resistive), and non-terminated. Client termination consisted of clients terminating against the advice of the therapist or failure to return for scheduled appointments. Client-therapist termination indicated that the client was cooperative and that therapy was terminated by mutual consent of the client and therapist with the client having made progress in treatment; that is, the client's behavioral adjustment had either improved or been maintained. Therapist termination (client 
referred) consisted of referral by the therapist to a more appropriate agency. Therapist terminated (client resistive) indicated that the client was in therapy but resistive to treatment services and, consequently, terminated by the therapist. Non-terminated indicated that the client remained in treatment at the time the checklist was circulated.

The therapists at Delaunay Institute were requested to provide a gross assessment of progress in therapy for the clients in the random sample. This was secured from Evaluation Checklist $I$, as shown in the Appendix. Identifying data on the client was provided on this form including the client's name and the date of initial interview. If appropriate, the name of the supervisee was also provided. The therapist had four possible categories for assessment of progress in therapy: great progress, moderate progress, slight progress, and no progress. The therapist was asked to evaluate the client, either at termination, or, if the client was still in treatment, at the time the checklist was circulated.

In addition to providing an assessment of the client's progress in therapy, the therapist was asked to determine the degree of certainty with which he made his assessment. There were three possible categories for degree of certainty: great certainty, moderate certainty, and slight certainty.

On both the Termination Checklist and the Evaluation Checklist I, a far right-hand column provided space for the client number. Each client in the random sample was assigned a client number prior to the circulation of the Termination Checklist and the Evaluation Check1ist I. Thus, the therapist could clip off and destroy the client 
names in the far right-hand column before this data left the clinic. This provision allowed for protection of client confidentiality. The range, means, and standard deviations were computed for the self pre PARS Scale factors and for the number of visits, progress in treatment as assessed by the therapist, and therapist certainty. Following this, correlations were computed for the random sample on number of visits, progress therapy, and the self pre PARS Scale factors. Tests of significance were applied to the outcomes of these correlations.

Methodology for Part Two of Study

The methodology for Part Two of this study is very similar to the methodology for Part One of the study with some appropriate alterations and additions.

As in Part One of this study, all clients in Part Two of this study, aged 16 to 64 , who came to the clinic between 11-21-72 and 7-21-73, were given the self pre PARS Scale at initial contact. In addition, the informant was given the informant pre PARS Scale under the same conditions described for Part One of this study. Moreover, the same methods were employed in attempting to secure unreturned informant pre PARS Scales from the informant.

Completed self and informant pre PARS Scales were, again, scored by the clinic secretary as indicated for Part One of the study and recorded on the self and informant PARS Scale Score Sheet (E11sworth, 1968) in the space provided for the pre scores. These raw scores were again converted into the standard scores described in Chapter III. 
In Part Two of this study, post scores were secured from clients who had remained in treatment for three months. As near as possible to the date of the initial clinic contact and three months later, the client was again administered the post PARS Scale at the clinic. In addition, the informant was administered the informant post PARS Scale either at the clinic, if available, or by mail. The informant was sent the informant post PARS Scale and a cover letter requesting that . he, again, rate the client on his current adjustment, pointing out that this would assist the clinic staff in determining if any changes had occurred. Again, the informant was asked to return the completed scale in the self-addressed, stamped envelope. Again, a follow-up request was sent in the event that the informant did not return the scale on the first request:

The self and informant completed post PARS Scales were scored by the clinic secretary and recorded on the self and informant PARS Scale Score Sheet (E1lsworth, 1968) in the space provided for post scores. These raw scores were then converted into the standard scores described in Chapter III.

Continuation in therapy was, again, determined by the number of visits to the clinic in a three-month period and secured from the billing cards. No distinctions were made with regard to kind of treatment. As in Part One of the study, therapist visits to a hospitalized patient were omitted. A three-month time period was, again, utilized to equalize the time differential for clients who 
initially contacted the clinic in November of 1972 and those contacting the clinic in July of 1973.

In October of 1973, the therapists at Delaunay Institute were requested to provide information on the non random sample in Part Two with regard to kind of termination, behavioral assessment, and therapist certainty in making the assessment. It is important to note that the therapist had contact with these clients over a threemonth period and it is probable that in most instances they could make their behavioral assessment on a basis of more frequent contact than for Part One of this study. Nevertheless, they were requested to make their assessment of this adjustment on or near the time the self and informant post PARS Scales were administered. They were requested to make this assessment in October of 1973 and, regardless of use of records, it may have been difficult to make an adequate assessment on or near the date of the administration of the post PARS Scales.

Kind of termination, as in Part one of this study, was indicated on the Termination Checklist shown in the Appendix. Again, there were five choices: client terminated, client-therapist terminated, therapist terminated (client referred), therapist terminated (client resistive), and non-terminated. These categories have been described in the preceding subsection of this chapter.

In Part Two of this study, the therapists at Delaunay were asked to provide a gross behavioral assessment for the clients in the non random sample as shown in Evaluation Checklist II in the Appendix. 
Unlike Part One of this study, it was requested that the therapist assess the client at or near the date on which the client and the informant were administered the post PARS Scale. The date of the post PARS Scale administration was provided the therapist on this checklist as part of the identifying data. Unlike Part One of this study, Evaluation Checklist II provided different categories for assessing the client's behavior. The therapist was provided four categories for behavioral assessment: improved, maintained, regressed (therapeutic), and regressed (non-therapeutic). Therapeutic regression was defined, for purposes of this evaluation checklist, as part of the therapeutic process or as being of ultimate benefit to the client.

Identifying data was also provided for the therapist on Evaluation Checklist II. This data included the client name, the date of the initial interview, and the date at which the client was to be evaluated. In the event that the therapist was a psychology intern or a social work trainee, the supervising therapist was provided the name of the supervisee. In some instances, it was possible to contact the supervisee and have him or her complete the evaluation checklist.

As in Part One of this study, the therapist was asked to provide an assessment regarding the degree of certainty with which he made the evaluation of the client's behavioral adjustment. The categories were the same as in Part One of this study, Evaluation Checklist I: great certainty, moderate certainty, and slight certainty. 
Again Evaluation Checklist II provided assigned client numbers in the far left-hand margin so that client names in the far righthand margin could be removed to protect client confidentiality. The range, means, and standard deviations were computed for the non random sample on the self pre and post PARS factors and on the informant pre and post PARS factors. The parametric $t$ was utilized in testing the significance of the differences in pre and post treatment groups after three months of clinic contact. In addition, the range, means, and standard deviations were computed on the non random sample for the number of treatment sessions, therapist behavioral assessment, and therapist certainty. Finally, correlations for the non random sample were computed to determine the relationship between the self and informant, pre and post, PARS factors; the number of treatment sessions; and the therapist's behavioral assessment.

\section{SUMMARY}

Part One of the present study focuses on continuation in therapy. It explores the self pre treatment adjustment of clients as assessed by the PARS Scale and attempts to relate the self pre treatment assessment on the PARS Scale factors to subsequent therapist assessment of progress in therapy, kind of termination, and number of clinic contacts. This part of the study focuses on all clinic contacts who have been administered the self pre PARS Scale. 
Part Two of this study concentrates on a non random sample of clients who have remained in treatment for three months or more. This part of the study attempts to emphasize treatment outcome as assessed by the self and informant, pre and post, PARS Scale factors and their relationship to duration of therapy, therapist behavioral assessment, and kind of termination. The sample in this part of the study is not randomly selected and is more clearly defined with regard to education, income, presenting problem, and other factors. Kind of treatment, as with the random sample, is not defined. Unlike Part One of this study, therapist assessments for Part Two are made for behavior at three months after initial contact and therapist assessment includes a category for behavioral regression in treatment. A limited exploration of a minimum of factors influencing continuation in treatment and treatment outcome is the effort of the present study. 
CHAPTER V

FINDINGS

Findings are reported separately, in this chapter, for Parts one and Two of this study.

\section{FINDINGS FOR PART ONE OF STUDY}

The findings for Part one of this study pertain to client pre treatment adjustment, continuation in therapy, and progress in therapy.

In Part one of this study and by random sample, it was found that seventy-three per cent of the sample was female and twenty-seven per cent was male.

Findings on Pre Treatment Adjustment

Essentially, the self pre PARS Scale scores on the random sample of seventy tend to show standard scores slightly below the mean of 50 on five PARS factors for both sexes and on the Anxiety factor for males and the Household Management factor for females. The range, means, and standard deviations are shown in Table I.

The self pre PARS Scale standard scores in this sample appear to be slightly below the mean standard score for both males and females on all of the factors indicated. Males tend to secure slightly higher scores than females and evidence a smaller range and standard deviation. Both males and females secure the lowest mean 


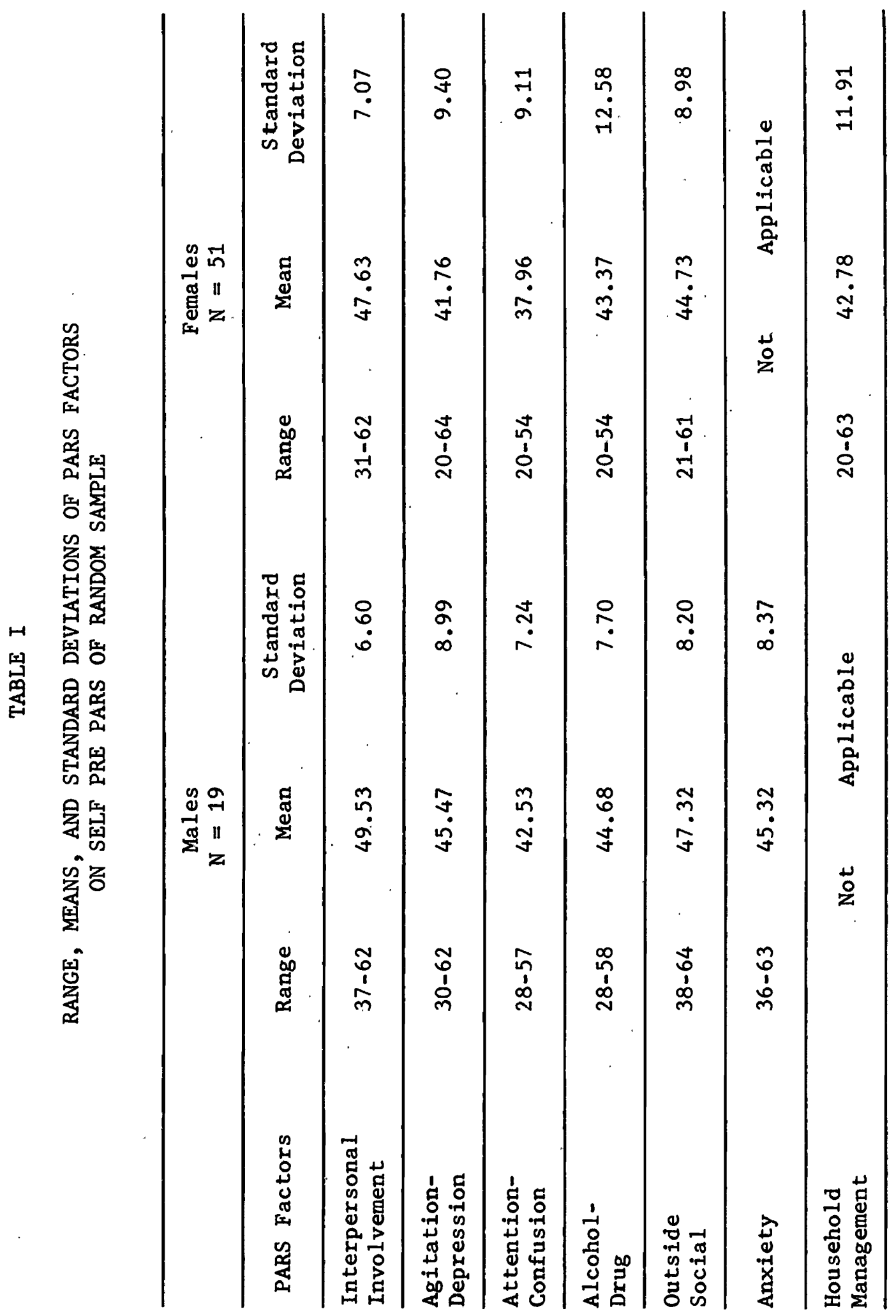


score on the Attention-Confusion factor and the highest mean score on Interpersonal Involvement.

Pre Treatment Adjustment from Previous PARS Studies

In this subsection the random sample, from Delaunay is compared with two other studies employing the PARS Scale and pre treatment scores.

The random sample from Delaunay Institute tends to show considerably higher pre self PARS Scale mean scores on all PARS factors than the sample from the study of Oregon State Hospital patients by Thorne and Goff (1972b, pp. 10-11). The means of self pre PARS Scale standard scores from both samples are compared in Table II.

It can be observed from Table II that the scores from the Delaunay sample are considerably higher for both males and females than the scores from the sample in the Thorne and Goff (1972a; 1972b) study. Both males and females in the Delaunay sample have scores that are approximately ten points higher on Interpersonal Involvement than those of the hospitalized population. With regard to AgitationDepression, the males in the Delaunay sample tend to score twenty points higher and the females ten points higher. On the AttentionConfusion factor the Delaunay sample males score twenty points higher and the females fifteen points higher. With regard to the AlcoholDrug factor the Delaunay males score forty points higher and the females thirty points higher than the Thorne and Goff sample. The Outside Social factor shows the Delaunay sample males scoring forty 
TABLE II

COMPARISON OF MEAN SCORES ON THE SELF PRE PARS FACTORS:

THE THORNE AND GOFF ${ }^{*}$ STUDY AND THE DELAUNAY SAMPLE

\begin{tabular}{|c|c|c|c|c|}
\hline & Thorne & and Goff & Delaunay & Sample \\
\hline PARS Factors & $\begin{array}{r}\text { Males } \\
\mathrm{N}=65\end{array}$ & $\begin{array}{r}\text { Females } \\
\mathrm{N}=93\end{array}$ & $\begin{array}{r}\text { Males } \\
\mathrm{N}=19\end{array}$ & $\begin{array}{r}\text { Females } \\
\mathrm{N}=51\end{array}$ \\
\hline $\begin{array}{l}\text { Interpersonal } \\
\text { Involvement }\end{array}$ & 37.05 & 35.00 & 49.52 & 47.63 \\
\hline $\begin{array}{l}\text { Agitation- } \\
\text { Depression }\end{array}$ & 22.78 & 29.31 & 45.47 & 41.76 \\
\hline $\begin{array}{l}\text { Attention- } \\
\text { Confusion }\end{array}$ & 23.35 & 22.80 & 42.53 & 37.96 \\
\hline $\begin{array}{l}\text { Alcohol- } \\
\text { Drug }\end{array}$ & 12.58 & 3.49 & 44.68 & 43.37 \\
\hline $\begin{array}{l}\text { Outside } \\
\text { Social }\end{array}$ & 9.40 & 14.34 & 47.32 & 44.73 \\
\hline Anxiety & 14.74 & $\begin{array}{c}\text { Not } \\
\text { Applicable }\end{array}$ & 45.32 & $\begin{array}{c}\text { Not } \\
\text { Applicable }\end{array}$ \\
\hline $\begin{array}{l}\text { Household } \\
\text { Management }\end{array}$ & $\begin{array}{c}\text { Not } \\
\text { Applicable }\end{array}$ & 31.95 & $\begin{array}{c}\text { Not } \\
\text { Applicable }\end{array}$ & 42.78 \\
\hline
\end{tabular}

points higher than the hospitalized sample and the females thirty points higher. On the Anxiety factor the Delaunay males score thirty points above the hospitalized males. With regard to the Household Management factor the Delaunay females show a score ten points above that of the hospitalized females. The noticeably higher mean scores of the outpatient Delaunay sample might be expected when compared with a hospitalized sample. 
However, the random sample from Delaunay Institute tends to show considerably higher self pre treatment scores on all the indicated factors when compared with the informant pre treatment scores from the Oregon community mental health clinic sample in the study done by Goff, Osborne, Campbel1, and Fletcher (1971, p. 16). It is important to recall that in that study only the informant provided pre and post PARS Scale scores. There were neither pre nor post self scores provided in that study. It is important to note that the tables in the Thorne and Goff study (1972b, pp. 10-11) show that the informant pre PARS assessment is very similar to the self pre PARS Scale assessment. Nevertheless, it is exceedingly important to remember that self and informant scores are being compared and that the comparison is suggestive at best.

The study of outpatients in Oregon community mental health clinics assessed data by treatment category for both males and females. The categories utilized were: Marriage and Family, Adult Psychiatric, and Child Guidance. The means of the pre treatment self scores from the Delaunay sample are compared with the pre treatment scores of the informant in the community mental health clinic sample by treatment category. The results appear in Table III.

From Table III, comparing Delaunay pre self scores and the Oregon mental health clinic pre informant scores, mean scores on all factors appear to be considerably higher for the Delaunay sample. Both males and females in the Delaunay sample tend to score ten points higher than those in the mental health clinic sample. On AgitationDepression and Attention-Confusion the Delaunay sample tends to show 


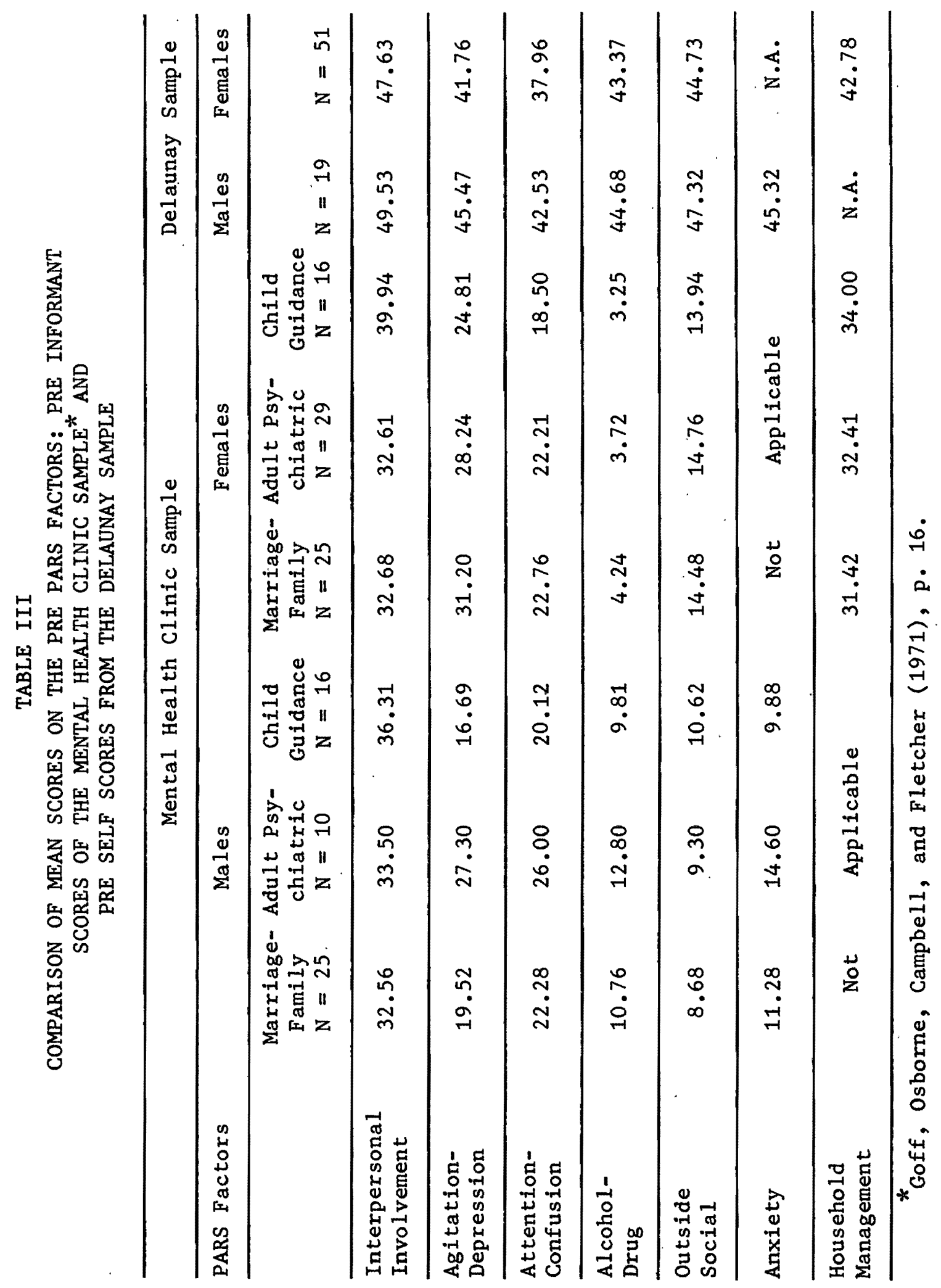


mean scores that are nearly twenty points higher for both males and females. In the Delaunay study the males on the Alcohol-Drug factor score nearly forty points higher and the females score nearly thirty points higher. With regard to the Outside Social factor, again, males tend to show mean scores forty points above those of the mental health clinic sample and the females scores that are nearly thirty points above the mental health clinic sample. In the Delaunay sample, males score thirty points above the mental health clinic sample on the male Anxiety factor. With regard to the female factor of Household Management, the females in the Delaunay sample score ten points above the mental health clinic sample.

Thus, it would appear that on all PARS factors the Delaunay sample shows excessively better initial adjustment than the Oregon community mental health clinic sample (Goff, Osborne, Campbell, and Fletcher, 1971). However, and again it is important to remember that the community mental health clinic sample is an informant rating and the Delaunay sample is a self rating. From past studies, it would appear that informant ratings have been very similar to self ratings in pre treatment assessment on the PARS Scale (Thorne and Goff, 1972b, pp. 10-11). In addition, while both are community mental health clinic samples, it is important to note that the Delaunay random sample included all applicants for treatment with the exceptions noted in Chapter IV. The Goff, Osborne, Campbe11, and Fletcher (1971) included only those clients remaining in treatment for three months or more. It would seem likely that clients 
remaining in treatment for three months would tend to be in greater need of treatment services and, therefore, initially show lower PARS Scale scores. Again, comparison of informant and self pre treatment PARS ratings are suggestive, at best.

\section{Findings on Treatment Outcome}

Treatment outcome for the random sample was assessed by means of number of clinic visits, progress in therapy, and kind of termination.

With regard to continuation in therapy the findings tend to show that the males remained in treatment for six sessions and the females remained for less than five sessions. In terms of progress in therapy and by therapist assessment, findings tend to indicate that both males and females in this sample made only slight progress in therapy and that these therapist assessments were made with only slight certainty. These findings are summarized in Table IV, providing the range, means and standard deviations on number of visits, therapist assessment, and therapist certainty.

Results from Table IV show that the greatest number of visits for the males is twenty-two and for the females, fourteen.

In the random sample and on a scale of one to four, with the greatest progress being indicated by the lowest number, the findings indicate that both males and females in this sample made only slight progress as assessed by the therapist. 
TABLE IV

RANGE, MEANS, AND STANDARD DEVIATIONS FOR RANDOM SAMPLE ON NUMBER OF VISITS, PROGRESS IN TREATMENT,

AND THERAPIST CERTAINTY

\begin{tabular}{|c|c|c|c|c|c|c|}
\hline \multirow[b]{2}{*}{$\begin{array}{l}\text { Outcome } \\
\text { Variable }\end{array}$} & \multicolumn{3}{|c|}{$\begin{array}{r}\text { Males } \\
\mathrm{N}=19\end{array}$} & \multicolumn{3}{|c|}{$\begin{array}{r}\text { Females } \\
\mathrm{N}=51\end{array}$} \\
\hline & Range & Mean & $\begin{array}{r}\text { Standard } \\
\text { Deviation }\end{array}$ & Range & Mean & $\begin{array}{r}\text { Standard } \\
\text { Deviation }\end{array}$ \\
\hline $\begin{array}{l}\text { Number of } \\
\text { Visits }\end{array}$ & $1-22$ & 6.58 & 6.17 & $1-14$ & 4.86 & 4.4 \\
\hline $\begin{array}{l}\text { Therapist } \\
\text { Assessment }\end{array}$ & $1-5$ & 3.26 & 0.99 & $1-5$ & 3.3 & 0.97 \\
\hline $\begin{array}{l}\text { Therapist } \\
\text { Certainty }\end{array}$ & $1-3$ & 1.95 & 0.91 & $1-3$ & 2.01 & 0.88 \\
\hline
\end{tabular}

In determining certainty of progress in therapy on a scale of one to three and with the greatest certainty being indicated by the lowest number, findings tend to show that therapist assessment tended to be made with moderate certainty for both males and females. There seems to be a minimal increase in degree of certainty with female clients.

Termination Checklists indicated that for the total random sample, sixty per cent of the clients were viewed as having been client terminated and making no progress in treatment. Twenty per cent were viewed as non-terminated and making moderate progress in treatment. Thirteen per cent were seen as client-therapist terminated and assessed as having made moderate to great progress in treatment. Of the total sample, six per cent were classified as 
therapist terminated and referred and one per cent was viewed as therapist terminated and resistive.

Correlations Between Pre Treatment Adjustment and Treatment Outcome Correlations between the self pre PARS Scale factors, number of visits, and therapist assessment of progress in therapy are shown in Table V.

\section{TABLE V}

CORRELATIONS FOR RANDOM SAMPLE ON NUMBER OF VISITS, PROGRESS IN TREATMENT, AND THE

PARS SCALE FACTORS

\begin{tabular}{|c|c|c|c|c|}
\hline \multirow[b]{2}{*}{ PARS Factors } & \multicolumn{2}{|c|}{$\begin{array}{r}\text { Males } \\
\mathrm{N}=19\end{array}$} & \multicolumn{2}{|c|}{$\begin{array}{l}\text { Females } \\
\mathrm{N}=51\end{array}$} \\
\hline & $\begin{array}{l}\text { Number of } \\
\text { Visits }\end{array}$ & Progress & $\begin{array}{l}\text { Number of } \\
\text { Visits }\end{array}$ & Progress \\
\hline $\begin{array}{l}\text { Interpersonal } \\
\text { Involvement }\end{array}$ &.- .25 & .39 & -.01 & .02 \\
\hline $\begin{array}{l}\text { Agitation- } \\
\text { Depression }\end{array}$ & -.36 & .39 & -.04 & $\because .02$ \\
\hline $\begin{array}{l}\text { Attention- } \\
\text { Confusion }\end{array}$ & -.42 & .37 & -.00 & .07 \\
\hline $\begin{array}{l}\text { Alcohol- } \\
\text { Drug }\end{array}$ & $-.48^{*}$ & .37 & .02 & -.09 \\
\hline $\begin{array}{l}\text { Outside } \\
\text { Social }\end{array}$ & .17 & .32 & .12 & .06 \\
\hline Anxiety & -.32 & .43 & Not & licable \\
\hline $\begin{array}{l}\text { Household } \\
\text { Management }\end{array}$ & Not & icable & .05 & .10 \\
\hline
\end{tabular}


Correlations between number of treatment sessions and the self pre PARS factors do not provide even remotely meaningful results with regard to the females in the random sample. Again, correlations of progress in therapy with the self pre PARS factors provide no meaningful results for females in the random sample.

For the males in the random sample, correlations between number of treatment sessions and the self pre PARS factors indicate that the higher the self pre PARS rating on all factors the fewer the number of treatment sessions. None of these correlations are statistically significant with the exception of the Alcohol-Drug factor. With regard to this factor there is a significant inverse relationship between the number of treatment sessions and the self pre PARS rating on the Alcohol-Drug factor $(\mathrm{r}=-.48, \mathrm{p}<.05)$. Concerning progress in therapy, Table $\mathrm{V}$ would seem to indicate that male clients with higher pre treatment scores on the PARS Scale tend to show greater progress in therapy as assessed by the therapist.

Finally, there is a significant inverse relationship between the number of treatment sessions and therapist assessment of progress in therapy $[r=-.81, p<.01$ (19 males); $r=-.74, p<.001$ (51 females)]. Findings strongly suggest that therapist assessment of greater progress in therapy is associated with a lesser number of treatment sessions for both males and females in the random sample. 


\section{FINDINGS FOR PART TWO OF STUDY}

The findings for Part Two of the present study pertain to both client pre treatment and post treatment adjustment as assessed by the self and informant on the PARS Scale, continuation in therapy, progress in therapy as assessed by the therapist, and kind of termination.

Findings on Completed Data Return

In the present study, the same self raters provided pre and post ratings on the self, and the same informant raters provided pre and post ratings on the same client.

Out of the total 249 applicants to Delaunay who were administered the PARS Scale, only sixteen per cent completed most of the self scales on both the pre and post PARS. Out of this same population of 249 clients, only eight per cent completed most of the scales on the informant pre PARS and some of the scales on the informant post PARS.

With regard to the non random sample for Part Two of the present study, sixty-seven per cent were females and thirty-three per cent were males. Out of the females in this sample, nearly all completed most of the self pre and post PARS data and seventy-five per cent of these females completed some of the informant pre and post PARS data. Regarding the males in this sample, only forty-six per cent completed any post informant PARS data, providing a very small sample of six. While statistical analyses were completed on 
these six, it was determined that this sample was excessively small for provision of any meaningful statistical analyses. Therefore, in Part Two of the present study, only the data from the females in this sample is presented. However, even with this limitation, informant post data remains minimal.

Findings on Self Pre and Post PARS Treatment Adjustment

The self pre and post PARS scores on the random sample of fifteen females tend to show scores below the mean standard score of 50 on five PARS factors with the exceptions of the pre Alcohol-Drug factor and the post Interpersonal Involvement factor. The range, means, and standard deviations for the self pre PARS scores and the self post PARS scores are shown in Table VI.

As can be observed from Table VI, self pre PARS scores on the non random sample tend to lie below the mean of 50 with the exception of the Alcohol-Drug factor. On the self pre. PARS, clients tend to secure the highest self ratings on the Interpersonal Involvement and the Alcohol-Drug factors and the lowest self ratings on the Household Management and Attention-Confusion factors.

On the self post PARS ratings, clients tend to show slightly higher self post ratings on all factors with the exception of the Alcohol-Drug factor in which they secure a rating three points lower than the rating on the self pre PARS. Again, on the self post PARS, clients tend to secure the highest ratings on the Interpersonal Involvement and Alcohol-Drug factors and the lowest ratings on the Household Management and Attention-Confusion factors. 


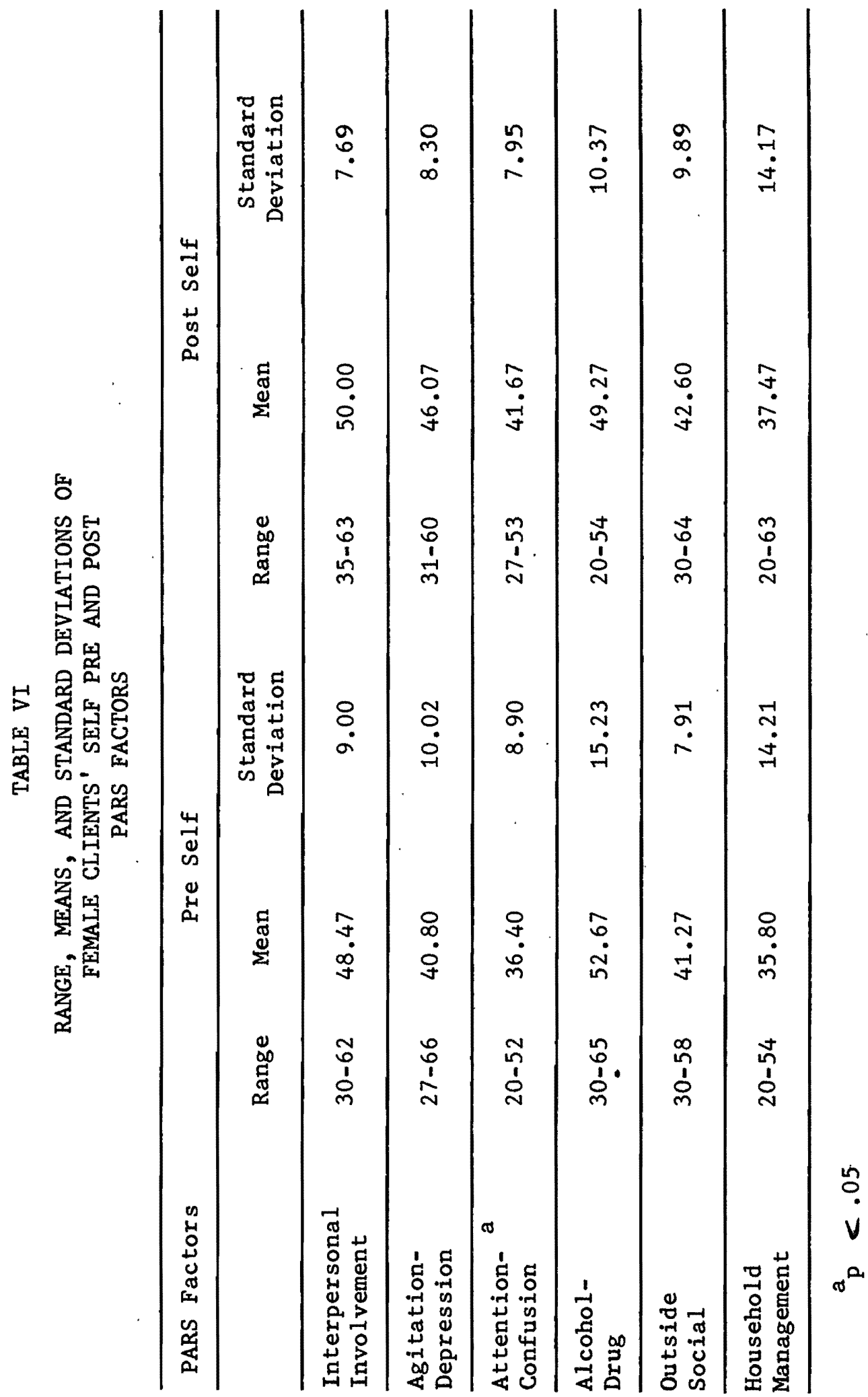


Statistical analyses, using the parametric $t$, were completed on all the self pre and post PARS factors: Interpersonal Involvement, Agitation-Depression, Attention-Confusion, Alcohol-Drug, Outside Social, and Household Management. None of the measures on the self pre and post PARS Scale were found to be statistically significant with the exception of the Attention-Confusion factor. The self pre Attention-Confusion factor and the self post Attention-Confusion factor were found to have a statistically significant difference (d.f. $28, t=1.71, p<.05$ on a one tailed test). This finding suggests a tendency to have statistically significant changes in the ability "to attend" following three months of treatment.

Findings on Informants' Pre and Post PARS Treatment Adjustment

Data on all of the six PARS factors for females was not available from the informant post PARS ratings as explained at the outset of this section. Complete data from informant pre and post PARS ratings was available only on the Attention-Confusion, Alcohol-Drug, and Outside Social factors.

The informant pre and post PARS Scale ratings on a non random sample of fourteen females tend to show scores below the mean score of 50 on the three available PARS factors with the exception of the informant post Alcohol-Drug rating. The range, means, and standard deviations for the informant pre PARS scores and the informant post PARS scores on the Attention-Confusion, Alcohol-Drug, and Outside Social factors are shown in Table VII. 


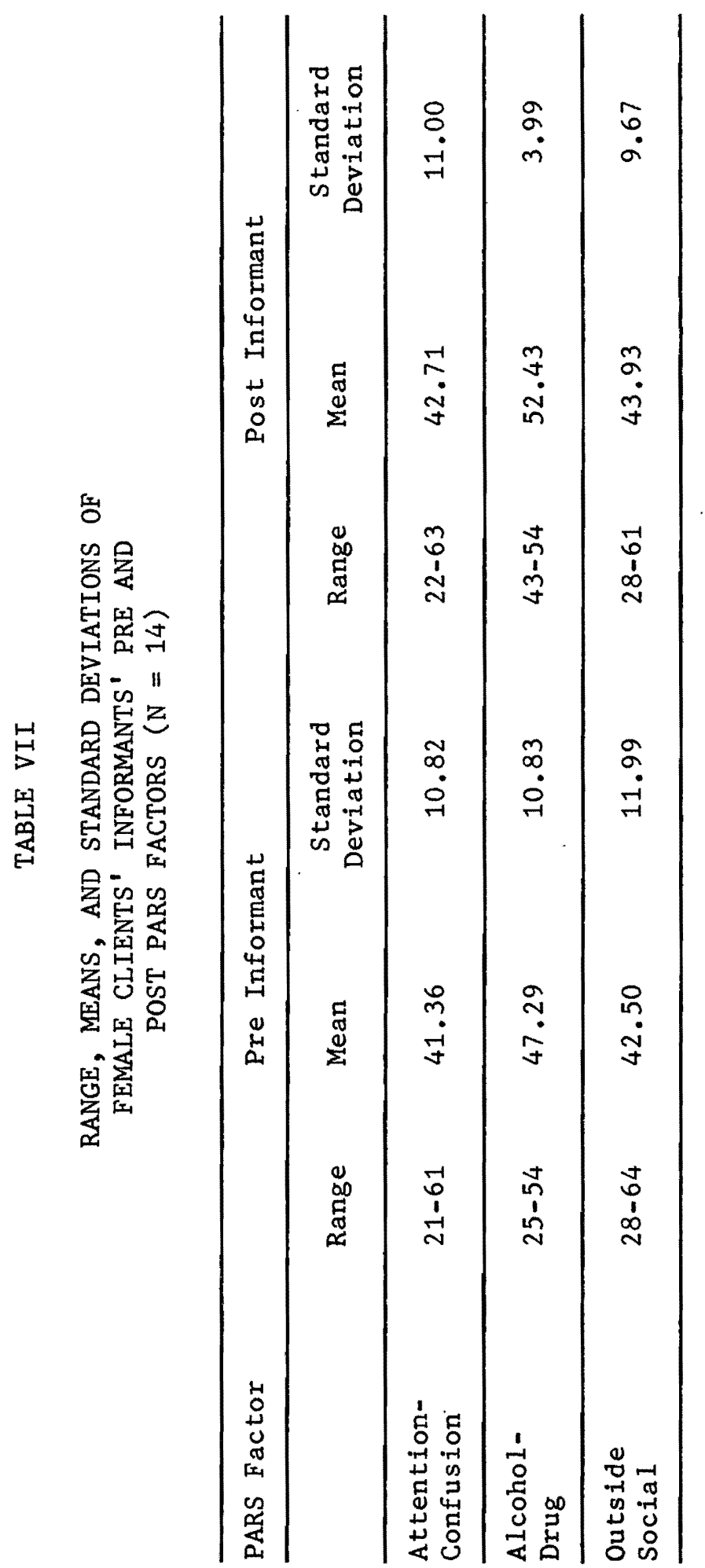


As can be observed from Table VII, there is a minimal difference between the informant pre PARS rating and the informant post PARS rating on the Attention-Confusion and the Outside Social factors and a difference of five points on the Alcohol-Drug factor.

Statistical analyses were completed on all three informant pre and post PARS factors: Attention-Confusion, Alcohol-Drug, and outside Social. No statistically significant differences were found on any of these factors.

Gross observations of Tables VI and VII indicate that on the Attention-Confusion and the Outside Social factors, the informant post PARS mean score shows greater similarity to the self post PARS mean score than do the self and informant pre PARS mean score on these factors. However, on the Alcohol-Drug factor the self pre PARS mean score shows greater similarity to the informant post PARS mean score.

\section{Findings on Treatment outcome}

Treatment outcome for the non random sample of fifteen females was determined by the number of treatment sessions, therapist behavioral assessment, and kind of termination.

With regard to continuation in therapy the findings tend to show that the fifteen females remained in treatment for slightly more than ten sessions. Therapist behavioral assessment showed either maintained or improved behavior and that therapists tended to make these assessments with moderate to great certainty. These findings are summarized in Table VIII, providing the range, means, and 
standard deviations on number of sessions, therapist behavioral assessment, and therapist certainty.

\section{TABLE VIII}

RANGE, MEANS, AND STANDARD DEVIATIONS OF NUMBER OF SESSIONS, THERAPIST BEHAVIORAL ASSESSMENT, AND THERAPIST CERTAINTY ON FEMALE CLIENTS $(\mathrm{N}=15)$

\begin{tabular}{lccc}
\hline Outcome Variable & Range & Mean & Standard Deviation \\
\hline Number of Visits & $3-27$ & 10.37 & 6.05 \\
\hline Therapeutic Progress & $1-2$ & 1.40 & 0.51 \\
\hline Therapist Certainty & $1-2$ & 1.33 & 0.49 \\
\hline
\end{tabular}

Concerning continuation in treatment, Table VIII indicates that these fifteen females averaged slightly more than ten visits. The minimal duration of treatment was three sessions in three months and the maximum duration of treatment was twenty-seven sessions in the same time period.

In the non random sample and on a scale of one to four, with the maximum behavioral adjustment, being indicated by the lowest number, findings indicate that these females tended to show improved behavioral adjustment or maintained behavioral adjustment by therapist assessment.

In determining certainty of therapist assessment of client behavioral adjustment on a scale of one to three and with the greatest certainty being indicated by the lowest number, findings tend to show that therapist behavioral assessment was made with moderate to great certainty. 
Regarding kind of termination for the non random sample, it was found that fifty-four per cent were non-terminated and assessed mainly as improved. Twenty-one per cent were viewed as client terminated and assessed as having either maintained or improved their behavioral adjustment. Eighteen per cent were viewed as client-therapist terminated and assessed as primarily improved. Three per cent were categorized as therapist terminated (resistive) and regressed in behavior.

Gross observations on the findings of treatment outcome for the non random sample of fifteen females and the random sample of 51 females show nearly twice as many average number of treatment visits, greatly increased behavioral adjustment as determined by the therapist, greater therapist certainty in assessment, and a greatly increased percentage of non-terminated clients for the non random sample of fifteen females.

Correlations Between Pre and Post PARS Treatment Adjustment and Treatment Outcome Factors

As previously noted, minimal data was secured on informant post PARS ratings and this deficiency is again observable with regard to the data in this subsection. The only informant post PARS correlation available in this subsection is the Alcohol-Drug factor.

Correlations between the self and informant, pre and post, PARS Scale factors and number of treatment sessions for the non random sample of fifteen females are shown in Table IX. 
TABLE IX

CORRELATIONS OF FEMALE CLIENTS' SELF AND INFORMANT

PRE AND POST PARS FACTORS WITH

NUMBER OF SESSIONS $(N=15)$

\begin{tabular}{|c|c|c|c|c|}
\hline PARS Factor & Pre Self & Post Self & $\begin{array}{c}\text { Pre } \\
\text { Informant }\end{array}$ & $\begin{array}{c}\text { Post } \\
\text { Informant }\end{array}$ \\
\hline $\begin{array}{l}\text { Interpersonal } \\
\text { Involvement }\end{array}$ & $a-.57$ & -.20 & -.07 & $-*^{*}$ \\
\hline $\begin{array}{l}\text { Agitation- } \\
\text { Depression }\end{array}$ & -.44 & -.24 & -.29 & -- \\
\hline $\begin{array}{l}\text { Attention- } \\
\text { Confusion }\end{array}$ & -.22 & .08 & -.03 & -- \\
\hline $\begin{array}{l}\text { Alcohol- } \\
\text { Drug }\end{array}$ & -.20 & $b^{\prime}-.68$ & -.34 & $\mathrm{a}-.52$ \\
\hline $\begin{array}{l}\text { Outside } \\
\text { Social }\end{array}$ & .27 & .12 & .13 & -- \\
\hline $\begin{array}{l}\text { Household } \\
\text { Management }\end{array}$ & -.29 & -.15 & -- & -- \\
\hline $\begin{array}{l}{ }^{*} \text { Data not } \\
{ }_{p}<.05 \\
{ }^{b_{p}}<.01\end{array}$ & vailable. & & & \\
\hline
\end{tabular}

As can be observed from Table IX, the relationship between the number of treatment sessions and the self and informant, pre and post, PARS factors tends to indicate that the higher the score on any of the PARS ratings indicated in Table IX, the fewer the number of treatment sessions, with the exception of the Outside Social factor.' On the Outside Social factor it would appear that the greater the score on this factor the more treatment sessions seem to be indicated. 
Statistically significant relationships appear on three of the PARS correlations shown in Table IX. There is a statistically significant and inverse relationship between the self pre PARS rating on Interpersonal Involvement and the number of treatment sessions $(x=-.57, \mathrm{p}<.05) . \quad$ A statistically significant and inverse relationship is indicated on the self post PARS Alcohol-Drug factor and the number of treatment sessions $(r=-.68, p<.01)$. Finally, a statistically significant and inverse relationship is apparent on the informant post PARS rating on the Alcohol-Drug factor and number of treatment sessions $(r=-.52, p<.05)$. Statistically significant analyses would appear to suggest that a high self pre PARS rating on Interpersonal Involvement and a high self and informant post PARS rating on the Alcohol-Drug factor is indicative of fewer treatment sessions.

Correlations between the self and informant, pre and post, PARS Scale factors and therapist behavioral assessment at three months of treatment for the non random sample of fifteen females are shown in Table $X$.

From Table $X$ it can be observed that a high self and informant, pre and post, rating on most PARS factors indicates a slight trend toward a favorable therapist behavioral assessment with the exceptions of the self pre scores on the Outside Social and the Household Management factors and the self post score on the Household Management factor. 
TABLE X

CORRELATIONS OF FEMALE CLIENTS' SELF AND INFORMANT

PRE AND POST PARS FACTORS WITH THERAPIST

BEHAVIORAL ASSESSMENT $(\mathrm{N}=15)$

\begin{tabular}{lcccc}
\hline PARS Factor & Pre Self & Post Self & $\begin{array}{c}\text { Pre } \\
\text { Informant }\end{array}$ & $\begin{array}{c}\text { Post } \\
\text { Informant }\end{array}$ \\
\hline $\begin{array}{l}\text { Interpersonal } \\
\text { Involvement }\end{array}$ & .27 & .45 & .23 & $--^{*}$ \\
\hline $\begin{array}{l}\text { Agitation- } \\
\text { Depression }\end{array}$ & .33 & .33 & $\mathrm{a} .51$ &.- \\
\hline $\begin{array}{l}\text { Attention- } \\
\text { Confusion }\end{array}$ & .20 & -.07 & .17 & .32 \\
\hline $\begin{array}{l}\text { Alcohol- } \\
\text { Drug }\end{array}$ & .03 & .39 & .11 & -- \\
\hline $\begin{array}{l}\text { Outside } \\
\text { Social }\end{array}$ & -.14 & $\mathrm{~b} .91$ & .29 & -- \\
\hline $\begin{array}{l}\text { Household } \\
\text { Management }\end{array}$ & -.13 & -.01 &.- &. \\
\hline
\end{tabular}

*Data not available.

$a_{p}<.05$

$\mathrm{b}_{\mathrm{p}}<.001$

Analyses of statistical significance indicate that there is a statistically significant and direct relationship between the informant pre PARS rating on Agitation-Depression and therapist behavioral assessment $(r=.51, p<.05)$. Furthermore, analyses of statistical significance indicate that there is a significant and direct relationship between the self post PARS rating on the Outside Social factor and therapist behavioral assessment $(r=.91, p<.001)$. 
Thus, it would appear that a high informant pre PARS rating on Agitation-Depression and a high self post PARS rating on Outside Social is indicative of increased behavioral adjustment as assessed by the therapist at three months of treatment.

\section{CONCLUSIONS}

Part One of Study

No relationship was found for females between number of treatment sessions and the self pre treatment PARS Scale ratings on Interpersonal Involvement, Agitation-Depression, Attention-Confusion, Alcohol-Drug, Outside Social, and Household Management factors.

No significant relationship was found for males between the number of treatment sessions and the self pre treatment PARS Scale ratings on Interpersonal Involvement, Agitation-Depression, AttentionConfusion, Outside Social, and Anxiety factors.

A significant inverse relationship was found for males between the number of treatment sessions and the self pre treatment PARS Scale rating on the Alcohol-Drug factor, indicating that the better initial adjustment the male client had on this factor, the fewer treatment sessions he had.

No relationship was found for females between therapist assessment of progress in therapy and the self pre treatment PARS scale ratings on Interpersonal Involvement, Agitation-Depression, AttentionConfusion, Alcohol-Drug, Outside Social, and Household Management factors. 
No significant relationship was found for males between therapist assessment of progress in therapy and the self pre treatment PARS Scale ratings on Interpersonal Involvement, AgitationDepression, Attention-Confusion, Alcohol-Drug, Outside Social, and Anxiety factors.

$\underline{\text { Part Two of Study }}$

No significant differences were found for females between the self pre and post treatment PARS Scale ratings on Interpersonal Involvement, Agitation-Depression, Alcohol-Drug, Outside Social, and Household Management factors after three months.

Significant differences were found for females between the self pre and post treatment PARS Scale ratings on the AttentionConfusion factor, indicating that there were significant changes in behavior on this factor after three months of treatment.

No significant differences were found for females between the informant pre and post treatment PARS Scale ratings on the AttentionConfusion, Alcoho1-Drug, and Outside Social factors after three months of treatment.

No significant relationship was found for females between number of treatment sessions and the self pre treatment PARS Scale ratings on the Agitation-Depression, Attention-Confusion, AlcoholDrug, Outside Social, and Household Management factors.

A significant inverse relationship was found for females between number of treatment sessions and the self pre treatment PARS Scale rating on the Interpersonal Involvement factor, suggesting 
that a high self pre treatment score on this factor was indicative of fewer treatment sessions.

No significant relationship was found for females between number of treatment sessions and the self post treatment PARS Scale ratings on Interpersonal Involvement, Agitation-Depression, Attention-Confusion, Outside Social, and Household Management factors.

A significant inverse relationship was found for females between number of treatment sessions and the self post treatment rating on the Alcohol-Drug factor, indicating that a high self post treatment score was indicative of fewer treatment sessions.

No significant relationship was found for females between number of treatment sessions and informant pre treatment PARS Scale ratings on Interpersonal Involvement, Agitation-Depression, Attention-Confusion, Alcohol-Drug, and Outside Social factors.

A significant and inverse relationship was found for females between number of treatment sessions and the informant post treatment PARS Scale rating on the Alcohol-Drug factor, indicating that a high informant post score on this factor was indicative of fewer treatment sessions.

No significant relationship was found for females between therapist behavioral assessment and self pre treatment PARS Scale ratings on Interpersonal Involvement, Agitation-Depression, Attention-Confusion, Alcohol-Drug, Outside Social, and Household Management factors. 
No significant relationship was found for females between therapist behavioral assessment and self post treatment PARS Scale ratings on Interpersonal Involvement, Agitation-Depression, Attention-Confusion, Alcohol-Drug, and Household Management factors.

A significant direct relationship was found for females between therapist behavioral assessment and the self post treatment PARS Scale rating on the Outside Social factor, indicating that a high self post treatment rating on this factor was suggestive of favorable therapist behavioral assessment after three months of treatment.

No significant relationship was found for females between therapist behavioral assessment and informant pre treatment PARS Scale ratings on Interpersonal Involvement, Attention-Confusion, Alcohol-Drug, and outside Social factors.

A significant and direct relationship was found for females between therapist behavioral assessment and the informant pre treatment PARS Scale rating on the Agitation-Depression factor, suggesting that an initially high informant rating on this factor was indicative of favorable therapist behavioral assessment after three months of treatment.

No significant relationship was found for females between therapist behavioral assessment and the informant post treatment PARS Scale rating on the Alcohol-Drug factor. 
IV. SUMMARY

Observations on Findings for Part One of Study

The random sample of 70 from Delaunay tended to secure scores slightly below the standard mean score of 50 on the self pre PARS Scale ratings on Interpersonal Involvement, Agitation-Depression, Attention-Confusion, Alcohol-Drug, Outside Social, male Anxiety, and female Household Management. As might be expected, these mean scores tended to be considerably higher than the self pre treatment scores of the hospitalized sample in the Thorne and Goff (1972b) study. However, they were also considerably higher than the informant pre treatment scores of the outpatient sample in the Goff, Osborne, Campbe11, and Fletcher (1971) study of Oregon community mental health clinics. In this study the sample consisted only of clients remaining in treatment for three months and ratings were done only by the informant.

The random sample evidences averages of approximately five clinic contacts for males and females. They were assessed as having made slight progress in therapy and therapists indicated slight certainty in making these assessments. In addition, findings suggested a strong significant relationship between favorable therapist assessment of progress and fewer treatment sessions. Finally, over half of the clients in this sample were categorized as client terminated.

Females in this sample evidenced no remote relationship between number of treatment sessions and self pre treatment PARS Scale 
ratings on the six factors. Again, females in this sample evidenced no remote relationship between therapist assessment of progress in therapy and self pre treatment PARS Scale ratings on the six factors. While statistically significant in only one instance, male outcomes made some suggestion of higher self pre treatment PARS scores being associated with fewer number of treatment sessions. While no statistically significant outcomes were obtained, male outcomes, again, made some suggestion of higher self pre treatment PARS scores being associated with greater progress in therapy.

\section{Observations on Findings for Part Two of Study}

In Part Two of the present study, post informant data was noticeably deficient. Consequently, Part Two of the study was limited to fifteen females and post informant data was extremely limited for this sample.

As in Part One of this study, self and informant pre and post PARS Scale scores were usually within ten points below the mean standard score of 50 . Slightly higher scores were usually secured on the self post PARS Scale ratings with the exception of the Alcohol-Drug factor which was lower on the self post rating.

In the non random sample of Part Two of the study, it was found that the sample averaged ten treatment sessions and showed improved or maintained behavior by therapist assessment with therapists evidencing moderate to great certainty in making this assessment. Half of the clients in this sample were classified as non-terminated. 
Findings regarding the relationship between number of treatment sessions and PARS Scale ratings and between therapist behavioral assessment and PARS Scale ratings tended to be somewhat more favorable with regard to the study hypotheses as is noted in the following subsection, Observations on Conclusions for Part Two of Study.

\section{Observations on Conclusions for Part One of Study}

With regard to the females in the random sample, there were no significant findings to support the proposition that higher self pre treatment ratings on the PARS Scale factors would be indicative of fewer treatment sessions. With regard to the males in this sample, only one PARS Scale factor, Alcohol-Drug, significantly suggested that a high self pre treatment rating on the PARS Scale was indicative of fewer treatment sessions.

With regard to both females and males in the random sample. there were no significant findings to support the proposition that higher self pre treatment ratings on the PARS Scale factors would be indicative of a favorable therapist assessment of progress in therapy. However, the findings on the males in this sample seemed to evidence a remote but non-significant trend in this direction.

\section{Observations on Conclusions for Part Two of Study}

Findings on the female clients in Part Two of this study were not generally supportive of the proposition that differences in self and informant, pre and post treatment, scores on the PARS Scale would measure changes in adjustment and behavior after three months of 
treatment. Self pre and post PARS Scale ratings were obtained on Interpersonal Involvement, Agitation-Depression, Attention-Confusion, Alcohol-Drug, Outside Social, and Household Management factors. Informant pre and post PARS Scale ratings were obtained on AttentionConfusion, Alcohol-Drug, and Outside Social. Only self pre and post treatment PARS Scale ratings on the Attention-Confusion factor evidenced significant differences after three months of treatment. Thorne and Goff (1972b) and Goff, Osborne, Fletcher, and Campbel1 (1971) also found the Attention-Confusion factor, among others, indicative of change after three months of treatment for both males and females.

With regard to females in the non random sample, three out of eighteen possible self and informant, pre and post treatment, PARS Scale ratings significantly supported the proposition that higher PARS Scale ratings would be indicative of fewer treatment sessions. The self pre treatment PARS Scale rating on Interpersonal Involvement, the self post treatment PARS Scale rating on Alcohol-Drug, and the informant post treatment PARS Scale rating on Alcohol-Drug significantly supported the proposition that higher PARS Scale ratings are indicative of fewer treatment sessions.

With regard to females in the non random sample, two out of eighteen possible self and informant, pre and post treatment, PARS Scale ratings significantly supported the proposition that higher PARS Scale ratings would be indicative of favorable therapist behavioral assessment at three months. The self post treatment PARS 
Scale rating on Outside Social and the informant pre treatment PARS Scale rating on Agitation-Depression significantly supported the proposition that higher PARS Scale ratings are indicative of favorable therapist behavioral assessment at the conclusion of three months of treatment.

By way of summary, while most PARS Scale ratings on most factors tended not to be significantly supportive of the study hypotheses, some limited but statistically significant support was given the study hypotheses in a few instances. The present study tends to suggest some limited support for the contention that higher PARS Scale ratings are indicative of fewer treatment sessions, particularly in Part Two of the present study. In Part One of the study, the self pre PARS rating on Alcohol-Drug significantly supported this hypothesis. In Part Two of the study, the self pre PARS rating on Interpersonal Involvement, the self post PARS rating on Alcohol-Drug, and the informant post PARS rating on Alcohol-Drug were supportive of this hypothesis. Again, Part Two of this study suggested some limited support for the contention that higher PARS Scale ratings are indicative of a more favorable therapist behavioral assessment. The self post PARS rating on Outside Social and the informant pre PARS rating on Agitation-Depression were supportive of this hypothesis. Finally, from a very limited non random sample of females, minimal support was afforded the contention that the PARS Scale can measure changes in behavior after three months of treatment. Significant differences on the self pre and post treatment PARS Scale rating on the Attention-Confusion factor were supportive of this hypothesis. 
CHAPTER VI

COMMENTS, CONCLUSIONS, AND RECOMMENDATIONS

It is the focus of this chapter to concisely summarize the efforts of the preceding chapters and provide commentary regarding future research efforts.

\section{COMMENTS AND CONCLUSIONS}

Treatment Sessions, Therapist Assessment, and Therapist Certainty

Findings in both parts of the present study with regard to mean number of treatment sessions might be anticipated in view of the description of the samples. A higher number of mean treatment sessions would be expected for the sample in Part Two of the study where clients were required to remain in treatment for three months or more.

Garfield (1971) has pointed out that the median number of treatment sessions is 5.5 when clients who have refused treatment have been excluded. In addition, the findings of Cole, Branch, and Allison (1962) indicate that lower socioeconomic groups are less likely to continue in treatment. Considering that the sample in Part one of this study did not eliminate those who refused treatment and considering the low-income status of the Delaunay catchment area, 4.86 (females) and 6.58 (males) might be considered a high mean number of treatment sessions for both sexes in the sample for Part One of this study. 
As was indicated in the preceding chapter, a much higher percentage of the sample for Part One of this study was client-terminated than in Part Two of this study. This might be anticipated in the sample for Part One where the mean number of treatment sessions varied between four to six sessions for females and males and when contrasted with a mean of 10 visits for Part Two of the study. Haddock and Mensh (1957) found that most non-continuers terminated of their own accord and without plan.

It would be anticipated that therapists would be able to make a more favorable assessment of adjustment for clients who have had more treatment sessions and do so with greater certainty. In Part Two of this study, this would appear to be supported. Therapist assessment of adjustment was more favorable for this sample and made with greater certainty. In Part one of this study, it was found that therapists viewed most clients as having made slight progress and did so with slight certainty. Nevertheless, it is important to note that in Part One of the study where therapists were able to make favorable assessments on adjustment, a strong inverse relationship was found with number of treatment sessions. This would seem to indicate that in these instances, limited treatment was associated with favorable initial assessment of client adjustment and that healthier clients had fewer treatment sessions. 
Number of Treatment Sessions, Therapist Assessment of Adjustment, and PARS Scale Factors

The pre treatment PARS Scale was not designed as a predictive instrument and in only two instances was any predictive capacity observable with this Scale. In Part One of the study, one male self pre treatment PARS rating Alcohol-Drug was significantly inversely related to number of treatment sessions. However, with the exception of Outside Social, all other PARS Scale factors for males showed a non significant but inverse relationship to number of treatment sessions so that more treatment sessions might be indicated for lowscoring male clients. For the females in Part one of the study, no relationship was found. In Part Two of the study, the females self pre PARS rating on Interpersonal Involvement was significantly predictive of fewer treatment sessions. In addition, in Part Two of this study, the self and informant post treatment PARS ratings on AlcoholDrug were found to be significantly associated with fewer treatment sessions. The Alcohol-Drug factor may warrant further exploration as a predictive factor with regard to number of treatment sessions. The pre treatment PARS Scale in Part One of this study showed no significant direct relationship between therapist assessment of progress in therapy and the PARS Scale factors. However, for males in this sample a non significant but direct relationship appeared for the PARS factors and progress in therapy. No relationship appeared for females in this sample. In Part Two of the study, the informant pre PARS rating for females on Agitation-Depression was significantly 
and directly related to therapist behavioral assessment, as was the self post PARS rating on the Outside Social factor. No specific PARS factor appears to be notably associated with therapist assessment of adjustment.

It is difficult to speculate on the possible reasons for the female sample in Part One of the study providing no indications of relationships between PARS Scale factors and number of treatment sessions, and between PARS Scale factors and therapist assessment of adjustment. Some relationship does appear on one informant pre PARS factor and one self post PARS factor in Part Two of the study. Females made up well over half of the random sample in Part One of the study. While the Scale was originally designed for hospitalized males, it has been shown in the present study to be able to make some discriminations with regard to females, as previously indicated, for Part Two of this study.

Considering that the PARS Scale was not designed for predictive purposes and does not appear to have notable predictive capacity from the present study, further research on its use for this purpose with regard to progress and duration of treatment would generally seem unwarranted. In addition, other adequate instruments for predictive purposes are available (Garfield, 1971).

Treatment Evaluation and the PARS Scale

In Part Two of this study, data was confined to female clients and post informant data was notably deficient for these clients. As in the Thorne and Goff (1972b) study, significant differences were 
found in female self pre and post PARS ratings on the AttentionConfusion factor after three months of treatment. In both, this factor was found to differentiate between pre and post treatment groups. However, in the Thorne and Goff (1972b) and the Goff, Osborne, Campbel1, and Fletcher (1971) studies, self and informant factors on Agitation-Depression, Interpersonal Involvement, and Household Management for females were also found to discriminate pre and post treatment groups. It was noted, previously, that in both of these studies that self and informant pre treatment ratings. were much lower than those in the Delaunay sample for both parts of the present study. It may be that where very fine discriminations are required for measuring pre and post treatment differences, the PARS Scale is inadequate. However, pre and post informant PARS Scale ratings were provided for only three PARS Scale factors: Attention-Confusion, Alcohol-Drug, and Outside Social. Thus, factors known to discriminate pre and post treatment groups on informant ratings were not available in this study.

\section{Methodology}

In Part Two of the present study, there is a notable lack of post informant data. Considering that one of the distinctive features about the PARS Scale is the evaluation by the informant, this is a severe deficit for Part Two of the present study. Provision of this data will be extremely important to further research on this Scale. 
In addition, in Part Two of this study, the sample is not random and was limited to females. A random sample including males would have provided greater validity.

As was previously noted, no demographic data was provided on the random sample and it was not identified with regard to presenting problem. In addition, the presenting problem was not identified for the sample in Part Two of this study. In Part Two of this study neither therapist variables nor treatment variables were identified. The present study does not succeed in meeting the specificity emphasized by Bergin and Strupp (1972):

Accordingly, he (the therapist) must succeed in defining "the problem" (that is the patient state to be modified), the kinds of personality and behavior changes to be achieved, and the procedure to be employed in reaching them (p. 436).

Summary

By way of conclusion and on the basis of limited findings, this study seems to suggest that better adjusted clients have fewer treatment sessions and, when in treatment, make better progress in therapy. While some proposed relationships do appear, it would seem that additional research on the PARS Scale as a predictive instrument is unwarranted since other adequate instruments have been designed specifically for this purpose. Additional research on the evaluative capacity of the PARS Scale with the recommendations noted seems warranted in view of the lack of a random sample including males for Part Two of the present study and the lack of post informant data in this part of the present study. 


\section{RECOMMENDATIONS}

While recommendations have accompanied comments and conclusions in the preceding section or have been implied, additional broad proposals are suggested in this section.

It would be anticipated, in future studies, that the PARS Scale might be employed for comparing two or more client samples exposed to different and identified treatment methods for similar kinds of presenting problems. Considering the low socioeconomic status of the Delaunay catchment area, it might be employed with groups receiving the "pre-therapy training" proposed by Truax and Carkhuff (1967) and groups not receiving this training.

While yet complex, it is hoped that future studies would attempt to employ the specificity with regard to patient, therapist, treatment, and outcome variables recommended by the psychotherapy researchers reviewed in this study. While the PARS Scale needs further exploration with a larger random sample including males and reflecting more post informant data, it is hoped that, at some future time, other means of treatment evaluation might be explored as well. The highly individualized treatment assessment explored by Kiresuk and Sherman (1968) and Shontz (1972) may be able to succeed in attempting to meet the specificity so strongly recommended by researchers (Kellner, 1967; Malan, 1973; and Strupp and Bergin, 1969). 
SOURCES CONSULTED

Affleck, D. Craig and Sarnoff A. Mednick. The Use of the Rorschach Test in the Prediction of the Abrupt Terminator in Individual Psychotherapy. Journal of Consulting Psychology, 1959, 23, 125-128.

Auld, Frank and Leonard D. Eron. The Use of the Rorschach Scores to Predict Whether Patients Will Continue in Psychotherapy. Journal of Consulting Psychology, 1953, 17, 104-109.

Bailey, M. A.; Warshaw, L.; and R. M. Eichler. A Study of Factors Related to Length of Stay in Psychotherapy. Journal of Clinical Psychology, 1959, 15, 442-444.

Barron, Frank. Some Test Correlates of Response to Psychotherapy. Journal of Consulting Psychology, 1953, 17, 234-241.

Berenson, Bernard G. and Robert Carkhuff (Eds.). Sources of Gain in Counseling and Psychotherapy. New York: Rinehart and Winston, 1967.

Bergin, Allen E. The Evaluation of Therapeutic Outcomes. In Allen E. Bergin and Sol L. Garfield (Eds.) Handbook of Psychotherapy and Behavior Change: An Empirical Analysis. New York: John Wiley and Sons, 1971.

Bergin, Allen E. and Sol L. Garfield (Eds.). Handbook of Psychotherapy and Behavior Change: An Empirical Analysis. New York: John Wiley and Sons, 1971.

Bergin, Allen E. and Hans H. Strupp. Changing Frontiers in the Science of Psychotherapy. Chicago: Aldine-Atherton, $1 \overline{972}$.

Block, Jack and Thomas Hobart. Is Satisfaction With Self a Measure of Adjustment? Journal of Abnormal and Social Psychology, 1955, 51, 254-259.

Breedlove, James L. Theory Development as a Task for the Evaluator. In Edward J. Mullen and James R. Dumpson (Eds.) Evaluation of Social Intervention. San Francisco: Jossey-Bass, 1972. Pp. 55-70.

Breedlove, James L. and Merton S. Krause. Evaluative Research Design: A Social Casework Illustration. In Louis A. Gottschalk and Arthur N. Auerbach (Eds.) Methods of Research in Psychotherapy. New York: Appleton, Century and Crofts, 1966. Pp. 456-477. 
Carr, John E. and John Whittenbaugh. Sources of Disagreement in Perception of Psychotherapy Outcomes. Journal of Clinical Psychology, 1969, 25, 16-21.

Cartwright, Rosalind Dymond and Barbara Lerner. Empathy, Need to Change, and Improvement in Psychotherapy. Journal of Consulting Psychology, 1963, 27, 138-144.

Cole, Nyla J.; Branch, C. Hardin; and Roger Allison. Some Relationships Between Social Class and the Practice of Dynamic Psychotherapy. American Journal of Psychiatry, 1962, 118, 10041012.

E11sworth, Robert B. Personal Adjustment and Role Skills Manual. Mimeographed, State of Oregon, Mental Health Division, 1968.

E11sworth, Robert B. Feedback: Asset or Liability in Improving Treatment Effectiveness. Mimeographed, Salem, Virginia, Veterans Administration Hospita1, 1973.

Ellsworth, Robert B. Consumer Feedback in Measuring the Effectiveness of Mental Health Programs. In Guttentag Strunig (Eds.) Handbook of Evaluation Research. In press.

E11sworth, Robert B. Factor Loadings on PARS Items. Personal Communication, Salem, Virginia, January 7, 1974.

Ellsworth, Robert B.; Dickman, Harold R.; and Robert J. Maroney. Characteristics of Productive and Unproductive Unit Systems in V. A. Psychiatric Hospitals. Hospital and Community Psychiatry, $1972,23,261-268$.

Ellsworth, Robert B.; Foster, Leslie; Childers, Barry; Arthur, Gilbert; and Duane Kroeker. Hospital and Community Adjustment as Perceived by Psychiatric Patients, Their Families, and Staff. Journal of Consulting and Clinical Psychology, 1968, $32,1-41$.

Ellsworth, Robert B. and Joan E11sworth. The Psychiatric Aide: Therapeutic Agent or Lost Potential. Journal of Psychiatric Nursing, $1970,8,7-13$.

Ellsworth, Robert B. and Robert J. Maroney. Characteristics of Psychiatric Programs and Their Effects on Patients' Adjustment. Mimeographed, Salem, Virginia, Veterans Administration Hospital, 1973.

Eysenck, Hans J. The Effects of Psychotherapy: An Evaluation. Journal of Consulting Psychology, 1952, 16, 319-324. 
Feifel, Herman and Janet Eells. Patients and Therapists Assess the Same Psychotherapy. Journal of Consulting Psychology, 1963, $27,310-318$.

Fischer, Joel. Is Casework Effective: A Review. Social Work, $1973,18,5-20$.

Ford, Donald H. Research Approaches to Psychotherapy. Journal of Counseling Psychology, 1959, 6, 55-60.

Ford, Donald H. and Hugh B. Urban. Systems of Psychotherapy: A Comparative Study. New York: John Wiley and Sons, 1965.

Friedman, Henry J. Patient Expectancy and Symptom Reduction. Archives of General Psychiatry, 1963, $8,61-67$.

Fulkerson, Samuel C. and John R. Barry. Methodology and Research on Prognostic Use of Psychological Tests. Psychological Bulletin, 1961, 58, 177-204.

Gallagher, James J. Test Indicators for Therapy Prognosis. Journal of Consulting Psychology, 1954, 18, 409-413.

Garfield, Sol L. A Note on Patients' Reasons for Terminating Therapy. Psychological Reports, 1963, 13, 61-67.

Garfield, Sol L. Research on Client Variables in Psychotherapy. In Allen E. Bergin and Sol L. Garfield (Eds.) Handbook of Psychotherapy and Behavior Change: An Empirical Analysis. New York: John Wiley and Sons, 1971. Pp. 271-298.

Geismar, Ludwig L. Thirteen Evaluative studies. In Edward J. Mullen and James R. Dumpson (Eds.) Evaluation of Social In-

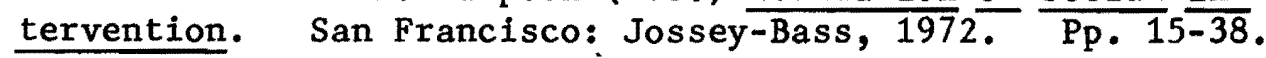

Goff, Clinton; Osborne, Gordon; Campbel1, K.; and M. Fletcher. Preliminary Report on the Use of the PARS Scale by Oregon's Community Mental Health Clinics. Mimeographed, State of Oregon, Mental Health Division, 1971.

Goldstein, Arnold P. Patients' Expectancies and Nonspecific Therapy as a Basis for (Un) Spontaneous Remission. Journal of Clinical Psychology, 1960, 16, 399-403.

Goldstein, Arnold P. Therapist-Patient Expectancies in Psychotherapy. New York: Macmillan, 1962 .

Goldstein, Arnold P. and Sanford Dean. The Investigation of Psychotherapy: Commentaries and Readings. New York: John Wiley, 1966. 
Goldstein, Arnold P.; Heller, Kenneth; and Lee B. Sechrest. Psychotherapy and the Psychology of Behavior. New York: John Wiley and Sons, 1966.

Goldstein, Arnold P. and William G. Shipman. Patient Expectancies, Symptom Reduction, and Aspects of the Initial Psychotherapeutic Interview. Journal of Clinical Psychology, 1961, 17, 129-133.

Grey, Alan L. and Helen E. Dermody. Reports of Casework Failure. Social Casework, 1972, 53, 534-543.

Haddock, James N. and Ivan N. Mensh. Psychotherapeutic Expectations in Various Clinic Settings. Psychological Reports, $1957, \underline{3}, 109-112$.

Hanson, Marsha11. Current Use of PARS Scale in Outcome Research in State of California. Personal Communication, Sacramento, California, Department of Mental Hygiene, December 28, 1973.

Heine, Ralph W. and Harry Trosman. Initial Expectations of the Doctor-Patient Interaction as a Factor in Continuance in Psychotherapy. Psychiatry, 1960, 23, 275-278.

Herzog, Elizabeth. Some Guide Lines for Evaluative Research: Assessing Psycho-Social Change in Individuals. Washington: U.S. Department of Health, Education, and Welfare, 1959.

Hiler, E. Wesley. Wechsler-Bellevue Intelligence as a Predictor of Continuation in Psychotherapy. Journal of Clinical Psychology, $1958,14,192-194$.

Hollingshead, August B. and Fredrick C. Redlich. Social Class and Mental Illness: A Community Study. New York: John Wiley and Sons, 1958 .

Imber, Stanley D.; Frank, Jerome D.; Gliedman, Lester H.; Nash, Ear 1 H.; and Anthony R. Stone. Improvement and Amount of Therapeutic Contact: An alternative to the Use of No-treatment Controls in Psychotherapy. Journal of Consulting Psychology, $1957,21,309-315$.

Imber, Stanley D.; Nash, Earl H.; and Anthony R. Stone. Social Class and the Duration of Psychotherapy. Journal of Clinical Psychology, 1955, 11, 281-284.

Isaacs, Kenneth S. and Ernest A. Haggard. Some Methods Used in the Study of Affect in Psychotherapy. In Louis A. Gottschalk and Arthur N. Auerbach (Eds.) Methods of Research in Psychotherapy. New York: Appleton, Century, and Crofts, 1966. Pp. 226-239. 
Kellner, Robert. The Evidence in Favour of Psychotherapy. British Journal of Medical Psychology, 1967, 40, 341-358.

Kiresuk, Thomas J. and Robert E. Sherman. Goal Attainment Scaling: A General Method for Evaluating Comprehensive Community Mental Health Programs. Community Mental Health Journal, 1968, $\underline{4}$, 443-453.

Levinger, George. Continuance in Casework and Other Helping Relationships: A Review of Current Research. Social Work, $1960, \underline{5}, 40-51$.

Lorr, Maurice; Katz, Martin M.; and Eli A. Rubenstein. The Prediction of Length of Stay in Psychotherapy. Journal of Consulting Psychology, 1958, 22, 321-327.

Lorr, Maurice; McNair, Douglas M.; Michaux, William W.; and Allen Raskin. Frequency of Treatment and Change in Psychotherapy. Journal of Abnorma1 and Social Psychology, 1962, 64, 281-292.

Luborsky, Lester; Auerbach, Arthur; Chandler, Michael; Cohen, Jacob; and Henry M. Bachrach. Factors Influencing the Outcome of Psychotherapy: A Review of Quantitative Research. Psychological Bulletin, 1971, 75, 145-182.

Malan, David H. The Outcome Problem in Psychotherapy Research: A Historical Review. Archives of General Psychiatry, 1973, 29, 719-729.

Mintz, Jim. What Is "Success" in Psychotherapy? Journal of Clinical Psychology, 1972, 80, 11-19.

Myers, Jerome K. and Lee L. Bean. A Decade Later: A Follow-up of Social Class and Mental Illness. New York: John Wiley and Sons, 1968 .

McNair, Douglas M.; Lorr, Maurice; and Daniel M. Callahan. Patient and Therapist Influences on Quitting Psychotherapy. Journal of Consulting Psychology, 1963, 27, 10-17.

McNair, Douglas M.; Lorr, Maurice; Young, Harl H.; Roth, Irvin; and Richard W. Boyd. A Three-year Follow-up of Psychotherapy Patients. Journal of Clinical Psychology, 1964, 20, 258-264.

Nichols, Robert C. and Karl Beck. Factors in Psychotherapy Change. Journal of Consulting Psychology, 1960, 24, 388-399.

Overa11, Betty and H. Aranson. Expectations of Psychotherapy in Lower Socioeconomic Class Patients. American Journal of Orthopsychiatry, 1962, 32, 271-272. 
Paul, Gordon L. Strategy of Outcome Research in Psychotherapy. Journal of Consulting Psychology, 1967, 31, 109-118.

Perlman, Helen Harris. Perspectives on Social Casework. Philadelphia: Temple University Press, 1971.

Raskin, Allen. Factors Therapists Associate with Motivation in Psychotherapy. Journal of Clinical Psychology, 1961, 17, $62-65$.

Rayner, E. H. and H. Hahn. Assessment for Psychotherapy: A Pilot Study of Psychological Test Indications of Success and Failure in Treatment. British Journal of Medical Psychology, 1964, 37, 331-342.

Riess, Bernard F. and Lewis W. Brandt. What Happens to Applicants for Psychotherapy. Community Mental Health Journal, 1965, 1, 175-180.

Reznikoff, Marvin and Laura C. Toomey. Evaluation of Changes Associated with Psychiatric Treatment. Illinois: Charles C. Thomas, 1959 .

Ripple, Lillian. Motivation, Capacity, and Opportunity: Studies in Casework Theory and Practice. Chicago: Social Service Monographs, University of Chicago, 1964.

Rogers, Lawrence S. and Kenneth R. Hammond. Prediction of the Results of Therapy by Means of the Rorschach Test. Journal of Consulting Psychology, 1953, 17, 8-15.

Rosenberg, Selig. The Relationship of Certain Personality Factors to Prognosis in Psychotherapy. Journal of Clinical Psychology, $1954, \underline{10}, 341-345$.

Rubenstein, Eli A. and Maurice Lorr. A Comparison of Terminators and Remainers in Outpatient Psychotherapy. Journal of Clinical Psychology, 1956, 12, 345-349.

Rudolph, Claire and John Cumming. Where Are Additional Psychiatric Services Most Needed? Social Work, 1962, 7, 15-20.

Schofield, William. The Structured Personality Inventory in Measurement of Effects of Psychotherapy. In Louis A. Gottschalk and Arthur N. Auerbach (Eds.) Methods of Research in Psychotherapy. New York: Appleton, Century, and Crofts, 1966, Pp. 536-550. 
Shontz, Franklin C. Research Methodology: Individuality in Evaluations of Treatment Effectiveness. Journal of Consulting Psychology, 1972, 19, 76-81.

Strupp, Hans H. and Allen E. Bergin. Some Empirical and Conceptual Bases for Co-ordinated Research in Psychotherapy: A Critical Review of Issues, Trends, and Evidence. International Journal of Psychiatry, 1969, I, 18-90.

Strupp, Hans H. and Allen E. Bergin. The Last Word on Psychotherapy Research: A Reply. International Journal of Psychiatry, 1969, I, $160-168$.

Strupp, Hans H.; Chassan, Jacob B.; and John Ewing. Toward the Longitudinal Study of the Psychotherapeutic Process. In Louis A. Gottschalk and Arthur H. Auerbach (Eds.) Methods of Research in Psychotherapy. New York: Appleton, Century, and Crofts, 1966. Pp. 536-550.

Strupp, Hans H.; Fox, Ronald E.; and Ken Lessler. Patients View Their Psychotherapy. Baltimore: Johns Hopkins, 1969 .

Strupp, Hans H.; Wallach, Martin S.; and Michael Wogan. Psychotherapy Experience in Retrospect: Questionnaire Survey of Former Patients and Their Psychotherapists. Psychological Monographs, 1964, 78, 11.

Sullivan, Patrick; Miller, Christine; and William Smelser. Factors in Length of Stay and Progress in Psychotherapy. Journal of Consulting Psychology, 1958, 22, 1-9.

Taulbee, Earl S. Relationship Between Certain Personality Variables and Continuation in Psychotherapy. Journal of Consulting Psychology, 1958, 22, 83-89.

Thorne, Gaylord L. and Clinton C. Goff. An Evaluation of Change Following Hospitalization as Viewed by the Patient and by a Significant Other. Paper Presented at the Western Psychological Association Meeting, Portland, Oregon, April 26-29, 1972 .

Thorne, Gaylord L. and Clinton C. Goff. Patients and Significant Others' Evaluation of Change Following Hospitalization and Community Clinic Treatment. Paper Presented at American Psychological Association Meeting, Honolulu, Hawaii, September 1-8, 1972. 
109

Truax, Charles B. and Robert R. Carkhuff. Concreteness: A Neglected Variable in the Psychotherapeutic Process. Journal of Clinical Psychology, 1964, 20, 264-267.

Truax, Charles B. and Robert R. Carkhuff. Toward Effective Counseling and Psychotherapy: Training and Practice. Chicago: Aldine Publishing Company, 1967.

Volsky, Theodore; Magoon, Thomas M.; Norman, Warren T.; and Donald P. Hoy. The Outcomes of Counseling and Psychotherapy. Mineapolis: University of Minnesota Press, 1965.

Wolpe, Joseph. Psychotherapeutic Efficacy and Objective Research. International Journal of Psychiatry, 1969, ㄱ, 157-159. 
APPENDIX

TERMINATION AND EVALUATION CHECKLISTS 


\section{(Therapist or Supervisor) \\ TERMINATION CHECKLIST}

Please indicate below the kind of termination for the client listed according to the categories described below:

1) Client terminated: Therapy was terminated against advice of therapist or client failed to return.

2) Client-therapist terminated: Client cooperative and therapy terminated by mutual consent of client and therapist with client having made progress in treatment; that is, behavioral adjustment was improved or maintained.

3) Therapist terminated: Therapy was terminated by therapist because:

a) client was referred to more appropriate agency

b) client was too resistive to treatment

4) Non-terminated: Client remains in treatment.

Please check one:

\begin{tabular}{|c|c|c|c|c|c|c|c|}
\hline \multirow[t]{2}{*}{$\begin{array}{l}\text { Client } \\
\text { Name }\end{array}$} & \multirow[t]{2}{*}{ Supervisee } & \multirow[t]{2}{*}{$\begin{array}{c}\text { Client } \\
\text { Terminated }\end{array}$} & \multirow[t]{2}{*}{$\begin{array}{l}\text { Client- } \\
\text { therapist } \\
\text { Terminated }\end{array}$} & \multicolumn{2}{|c|}{$\begin{array}{l}\text { Therapist } \\
\text { Terminated }\end{array}$} & \multirow[t]{2}{*}{$\begin{array}{l}\text { Non-ter- } \\
\text { minated }\end{array}$} & \\
\hline & & & & 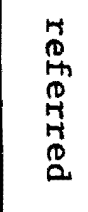 & 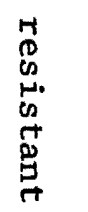 & & \\
\hline & & & & & & & \\
\hline & & & & & & & \\
\hline & & & & & & & \\
\hline & & & & & & & \\
\hline
\end{tabular}




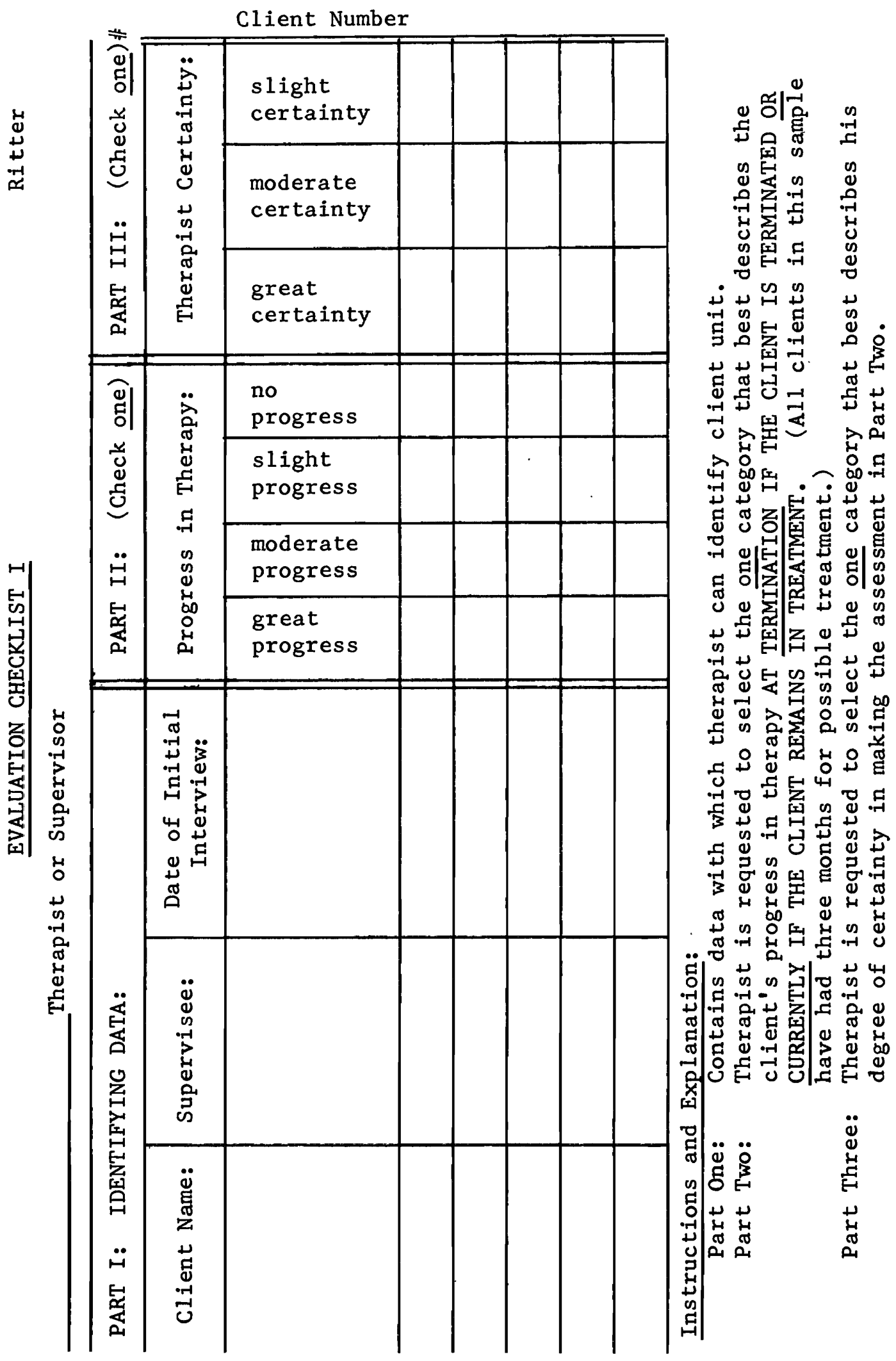




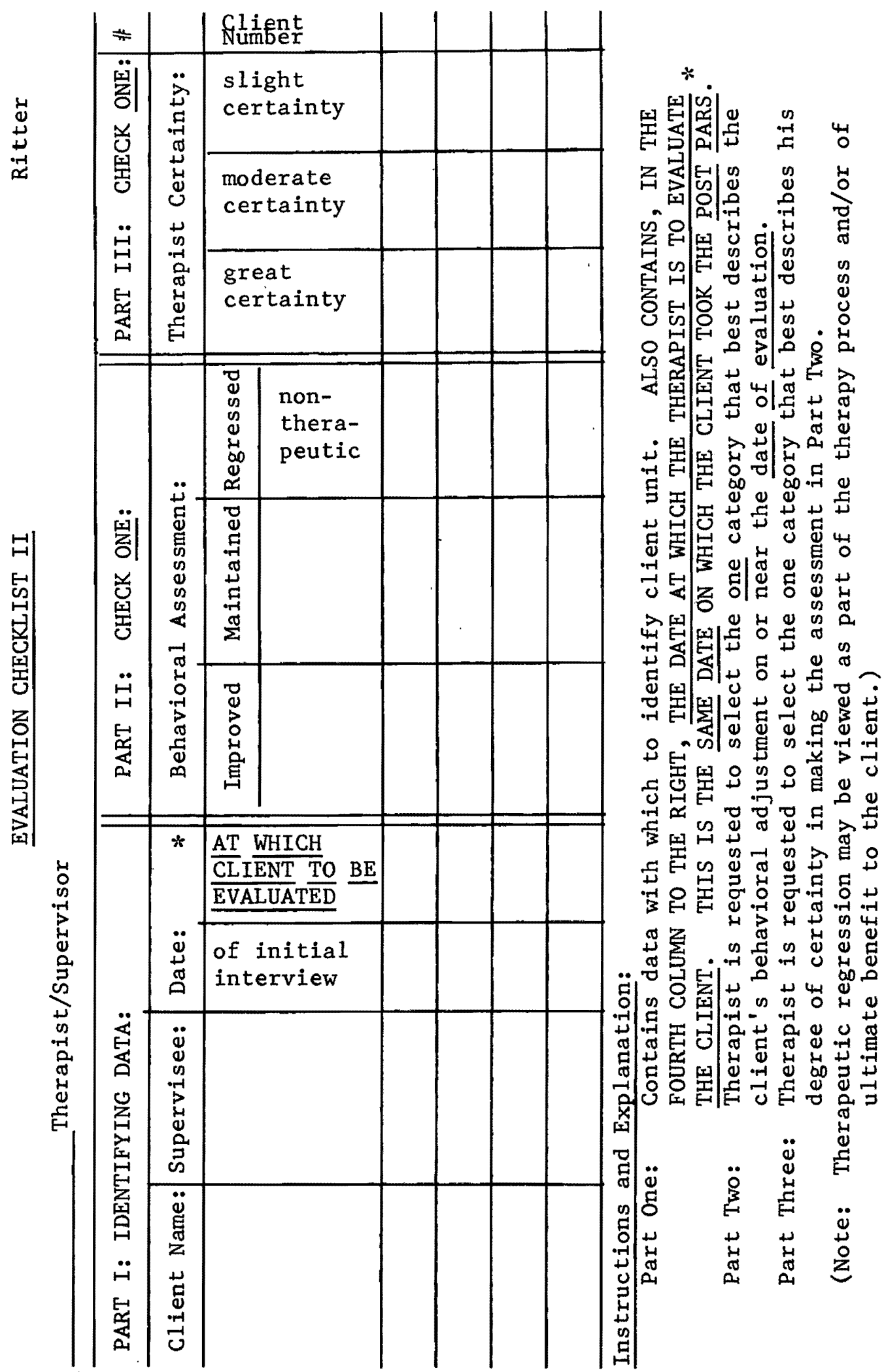

